\title{
Factor Structure and Distinctiveness of the Violence Propensity Vignette Questionnaire (VPVQ)
}

\author{
by
}

Alicia R. LaPierre

A thesis submitted to the Faculty of Graduate and Postdoctoral Affairs in partial fulfillment of the requirements for the degree of

Master of Arts

in

Psychology

Carleton University

Ottawa, Ontario

(C)2019

Alicia R. LaPierre 


\begin{abstract}
Measuring violence has been challenging due to differing perspectives and methodological issues. Nunes, Hermann, Maimone, Atlas, and Grant (2019) recently developed and initially validated the Violence Propensity Vignette Questionnaire (VPVQ) as a proxy measure to assess propensity for violent behaviour applicable to both community and forensic/correctional populations and settings. The current study used exploratory factor analysis (EFA) and examined semi-partial correlations to determine the factor structure of the VPVQ vignettes and response options, and the distinctiveness of the VPVQ in the developmental sample of community males. A 1-factor structure emerged for the vignettes, and the semi-partial correlations suggest a small but unique significant contribution. These results suggest that the VPVQ is measuring a unique construct independent of the comparison measures. The VPVQ response options EFA was problematic. Possible explanations for the emergent factor structures, challenges, and future directions for research and use of the VPVQ are discussed.
\end{abstract}

Keywords exploratory factor analysis; factor structure; violence, VPVQ; distinctiveness, psychometrics 


\section{Acknowledgements}

I would first like to sincerely thank my supervisor, Dr. Kevin Nunes, for his patience and guidance throughout the completion of this thesis. Thank you for believing in my ability to complete this project and for helping me to bring it to completion. I would also like to express my sincere gratitude to my committee members, Drs. Shelley Brown, Andrea Howard, and George Pollard, for the wisdom and expertise that they contributed to the completion of my thesis. Your time, patience, and knowledge were invaluable to my success.

I would also like to thank Etelle Bourassa and the Department of Psychology Graduate Administrative staff, for being lifesavers more times than I can possibly count. You make the department work.

Next, to the friends and colleagues I have met during this degree, thank you for your support and friendship. This degree would have been so much different without you along for the ride. You are all great. Also, to those friends who have been there since before this degree, you supported me where you could, and I am grateful for it.

Finally, to my loving husband and family, without whom I would not be where I am today. Your love and support are the glue that held me together through everything that has happened throughout this degree, and my life. A line in the acknowledgement section is not nearly enough to thank you for everything you have done for me, but it is a start. Mom, this one is dedicated to you.

Alicia LaPierre 


\section{Table of Contents}

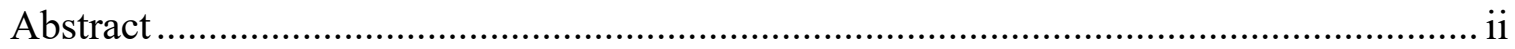

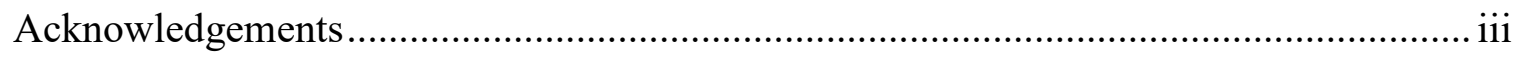

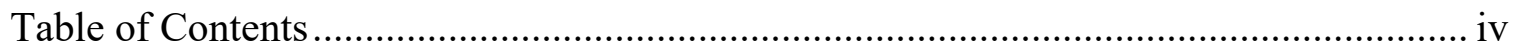

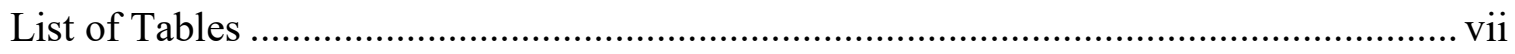

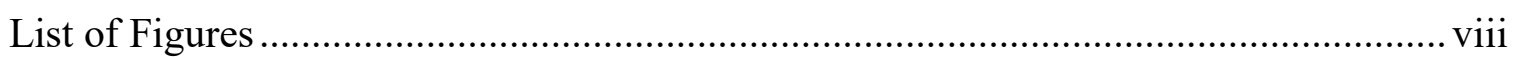

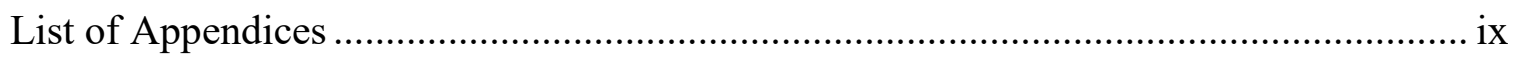

Factor Structure and Distinctiveness of the Violence Propensity Vignette Questionnaire

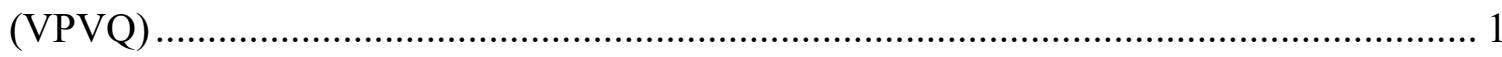

The Impact of Violence: Costs and Consequences of Violent Crimes ............................. 3

Mental and physical consequences of violent crime........................................... 3

Economic costs of violence in Canada. .................................................................. 4

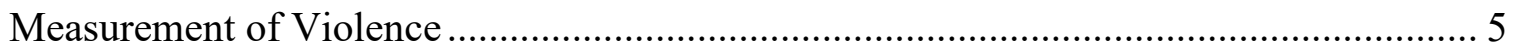

Challenges of measuring violence: construct operationalization................................ 5

Challenges of measuring violence: sources of data. ............................................. 5

Challenges of measuring violence: base rates. ................................................ 6

Challenges of measuring violence: lab versus field studies................................... 6

The Violence Propensity Vignette Questionnaire (VPVQ) ...................................... 8

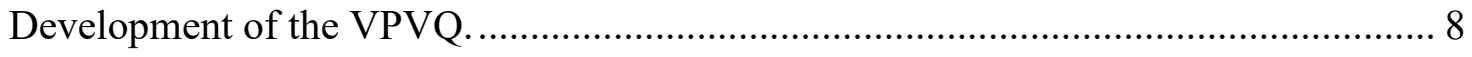

VPVQ validation with community men and male inmates. ............................... 9

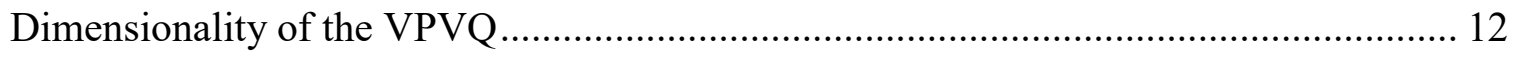

Evidence for possible unidimensionality: reactive vs proactive violence. .................. 12

Reactive-proactive dichotomy and the VPVQ vignettes. ................................... 13 
Evidence for unidimensionality: status threat................................................... 14

Evidence for possible multidimensionality: sexual possession threat. ...................... 15

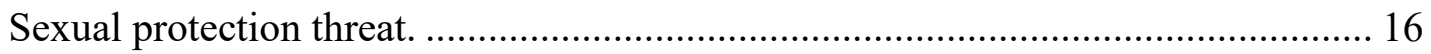

Is the VPVQ Distinct from Other Measures of Aggression or Violence? ....................... 17

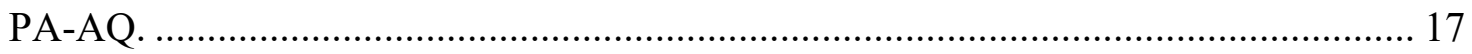

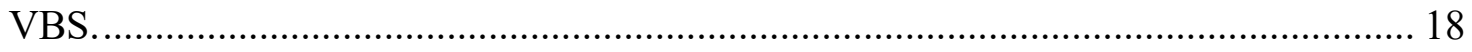

How might the VPVQ be unique from these measures? ..................................... 18

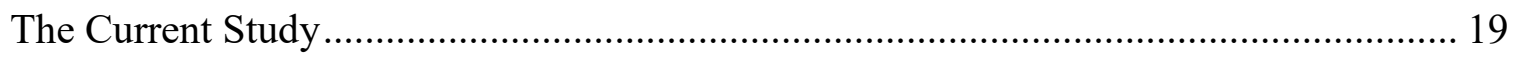

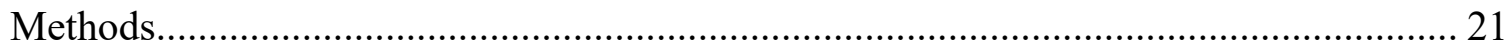

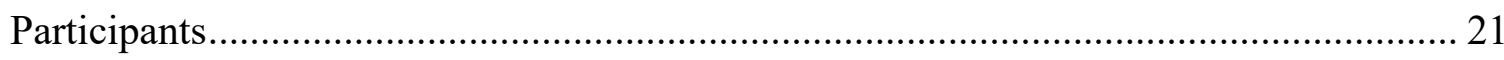

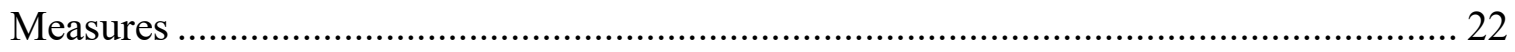

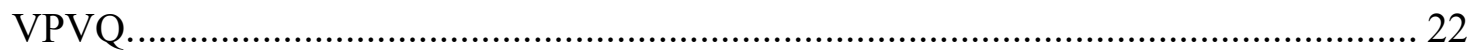

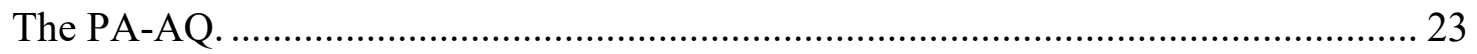

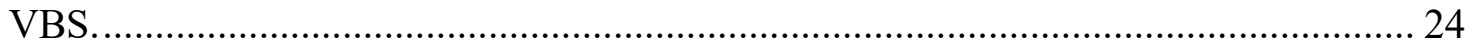

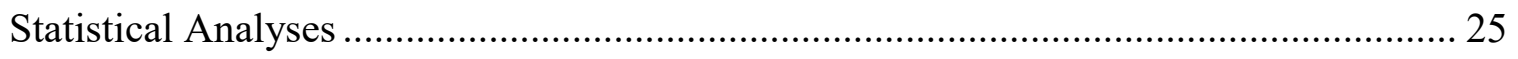

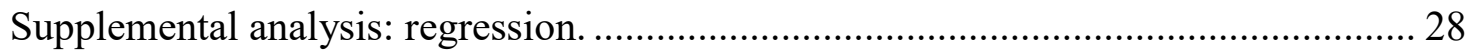

Supplemental analysis: response options EFA. ............................................... 29

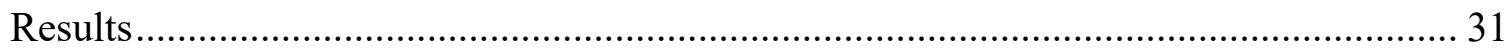

Underlying Factor Structure of the VPVQ Vignettes .......................................... 31

Distinctiveness of the VPVQ from other Measures.................................................. 35

Factor Structure of the VPVQ Response Options................................................. 44

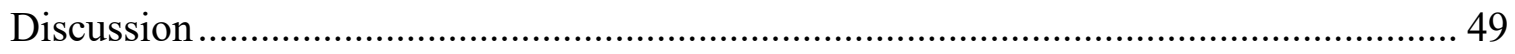


VPVQ Factor Structure \& Distinctiveness ……………............................................... 50

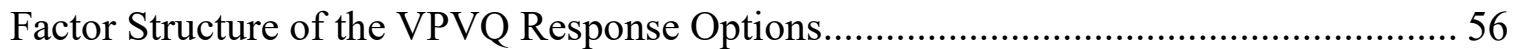

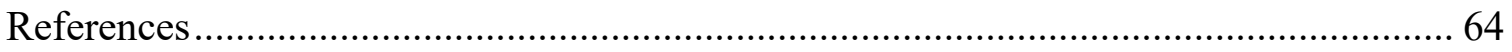

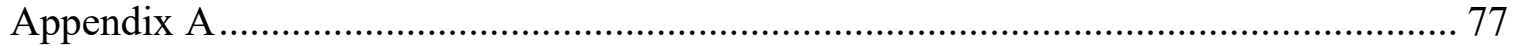

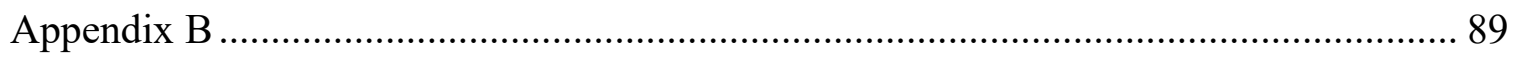

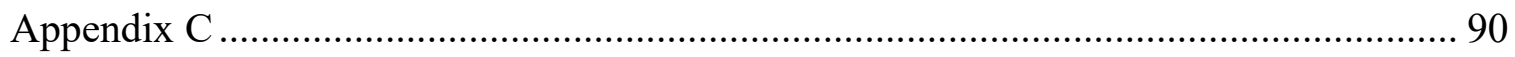

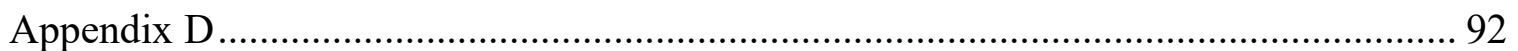




\section{List of Tables}

Table 1. Polychoric Correlations Between the Dichotomized Vignette Responses

Table 2. Factor Loadings for Exploratory Factor Analysis with Oblique Rotation of VPVQ Vignettes (1-Factor)

Table 3. Factor Loadings for Exploratory Factor Analysis with Oblique Rotation of the VPVQ (2-Factor)

Table 4. Polychoric Correlations Between the Items of the VPVQ, PA-AQ, and VBS 38

Table 5. Factor Loadings for Exploratory Factor Analysis with Oblique Rotation of the VPVQ, PA-AQ and VBS Items

Table 6. Hierarchical Multiple Regression Examining the Independent Association between the PA-AQ, the VPVQ, and VBS Mean Scores

Table 7. Hierarchical Multiple Regression Examining the Independent Association between the VBS, the VPVQ, and the PA-AQ Mean Scores

Table 8. Hierarchical Multiple Regression Examining the Independent Association between the PA-AQ, the VPVQ, and the VBS Factor Scores

Table 9. Hierarchical Multiple Regression Examining the Independent Association between the VBS, the VPVQ, and the PA-AQ Factor Scores

Table 10. Polychoric Correlations Between the Dichotomized Response Options

Table 11. Factor Loadings for Exploratory Factor Analysis with Oblique Rotation of VPVQ Response Options (1-Factor)

Table 12. Spearman Correlations Examining the Relationships Between the Dichotomized Response Options and the Mean Scores of the PA-AQ and the VBS 


\section{List of Figures}

Figure 1. Scree plot for exploratory factor analyses of the VPVQ vignettes.

Figure 2. Scree plot for exploratory factor analyses of the distinctiveness of the VPVQ from the PA-AQ and the VBS.

Figure 3. Scree plot for exploratory factor analyses of the dichotomized VPVQ response

options.

Figure 4. Scree plot for exploratory factor analyses of the continuous VPVQ response options.. 


\section{List of Appendices}

Appendix A: Violence Propensity Vignette Questionnaire (VPVQ)............ 77

A.1 Vignette 1: Obnoxious Roommate............................ 78

A.2 Vignette 2: Line Cutter..................................... 80

A.3 Vignette 3: Beer Bump.................................... 81

A.4 Vignette 4: Beer Run....................................... 82

A.5 Vignette 5: Threat........................................ 83

A.6 Vignette 6: Unwanted Guest................................ 84

A.7 Vignette 7: Obnoxious Guy in Line............................. 85

A.8 Vignette 8: Intimate Partner Violence......................... 86

A.9 Vignette 9: Interloper...................................... 87

A.10 Vignette 10: Disrespecting your Girlfriend/Wife................. 88

Appendix B: Physical Aggression Scale of the Aggression Questionnaire........ 89

Appendix C: Violent Behaviour Scale.................................. 90

Appendix D: EFA Results and Factor Loadings for the 2- and 3-Factor Models for the Dichotomized Response

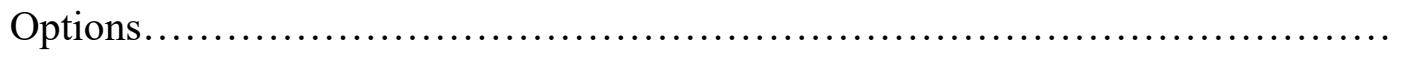

Appendix E: Descriptive Statistics for the Continuous Variable VPVQ Response Options. 
Factor Structure and Distinctiveness of the Violence Propensity Vignette Questionnaire (VPVQ)

Violence presents a serious problem for victims and perpetrators. Measuring violence has been challenging due to differing perspectives and methodological issues. Nunes, Hermann, Maimone, Atlas, and Grant (2019) recently developed the Violence Propensity Vignette Questionnaire (VPVQ) as a proxy measure to assess propensity for violent behaviour applicable to both community and forensic/correctional populations and settings. The VPVQ vignettes were developed using both clinical and research sources, with the aim of creating a measure of current propensity for violence that was valid for use with forensic and non-forensic samples. The VPVQ was initially tested and validated on both a community and correctional sample of adult males.

Nunes and colleagues (2019) proposed two questions for the future directions of the VPVQ. The first was that it is necessary to examine the factor structure of the vignettes. They suggested that the VPVQ may be unidimensional, and that it may be measuring reactive but not proactive violence. They attributed this hypothesis to the vignettes contents' emphasis on responding to an initial aggression against the participant, rather than the participant being the initial aggressor. However, no studies have yet investigated this claim. Other explanations of male violence such as differential responding to relationship threat cues may suggest that these kinds of vignettes may suggest a multidimensional structure. Therefore, it is necessary to consider the context or 
contexts in which the reactive-proactive dichotomy and other explanations of violence are relevant to the dimensionality of the VPVQ.

Additionally, Nunes and colleagues (2019) have proposed that it is important to examine the distinctiveness of the VPVQ from other measures of aggression and violence, such as the Violent Behaviour Scale (VBS; Nunes, Hermann, Maimone, \& Woods, 2016) or the Aggression Questionnaire (AQ; Buss \& Perry, 1992). It is important to examine to what extent the VPVQ can adequately measure violent behaviour, but it is also important to examine whether it does so in a way that is unique from other measures which are already in use. The VPVQ is more complicated to administer than other selfreport measures of violence and requires greater use of technology for administration. Therefore, it would be necessary to examine whether the VPVQ provides unique information, above and beyond established measures.

In summary, necessary next steps for the VPVQ are to examine the factor structure and distinctiveness of the measure. After discussing the challenges of studying violence, I outline the development of the VPVQ and speculate on various explanations for the possible factor structure of the VPVQ. Finally, I will discuss the distinctiveness of the VPVQ. Specifically, I will address how this question will expand upon the initial validation work of the original Nunes and colleagues' (2019) study and suggest some ways in which the measure might be unique from other measures of aggression and violent behaviour. Following that, I will outline my methodology for conducting exploratory factor analysis (EFA) and hierarchical multiple regression to investigate these questions. Due to the exploratory nature of this study, I do not propose any specific hypotheses. Nunes and colleagues (2019) posit that the items of the VPVQ will present 
with a unidimensional factor structure, though evidence from other branches of psychology might suggest a multidimensional structure. If the measure is non-redundant, it should factor separately from the other measures, and should have a unique association with responding on each of the other measures, above and beyond the other.

\section{The Impact of Violence: Costs and Consequences of Violent Crimes}

Violent crimes account for roughly one-fifth (21\%, Allen, 2018, p. 13) of all police-reported crimes in Canada, with over 403,000 reported incidents in 2017 (Allen, 2018). This rate increased by 5\% from the previous year. Importantly, while self-reported non-sexually violent crime victimization may occur similarly among males and females, perpetration of both sexual and nonsexual violence in 2014 was committed more often by males ( $86 \%$ of violent incidents overall). For sexually violent crimes, the perpetration rate was further skewed $(94 \%$ of the sexual violence perpetrators were males, versus $82 \%$ of the non-sexual violence perpetrators; Perrault, 2015).

Mental and physical consequences of violent crime. As reported by Perrault (2015), about one in seven victims of non-spousal violent crime have experienced symptoms suggestive of Post Traumatic Stress Disorder (PTSD), with anger being the most frequently reported emotional experience $(30 \%$, p. 20$)$. This was followed by just over $20 \%$ of victims reporting feeling "upset, confused, frustrated" and around 17\% feeling fearful. Relatedly, those who experienced violent victimization also reported experiencing depression and anxiety attacks significantly more than those who experienced household victimization (i.e., break and enter, theft, vandalism; $6 \%$ vs $1 \% ;$ p. 20$)$, and victims who experienced 
more severe intimate partner violence also experienced more negative outcomes (Ansara \& Hindin, 2011). Victims of violent crimes also suffer generally severe physical injuries (Shepherd, Shapland, Pearce, \& Scully, 1990). Finally, males who are exposed to violence in adolescence are at an increased risk of perpetrating violent behaviour both in the short-term, and up to 12-years later, independently of individual, family, or neighbourhood factors (Farrell \& Zimmerman, 2018).

Economic costs of violence in Canada. Violent crime also poses a heavy economic burden on both the Canadian criminal justice system and the Canadian people. In 2009, violent crimes amounted to a total estimated cost of $\$ 12.6$ billion (Hoddenbagh, Zhang, \& McDonald, 2014). This includes personal, justice system, and third-party (i.e., employer losses and social services operating) costs. More specifically, costs related to non-spousal, non-sexual violent crimes were estimated to be roughly $\$ 7.8$ billion. Victims incurred the highest total costs across all types of violent crimes, with male victims bearing the highest costs for all but sexually violent crimes. Justice system costs followed a similar, though lower, rate to that of victim costs. Third-party costs demonstrated a lesser, though still significant amount ranging from $\$ 12$ to $\$ 75$ million depending on the type of violent crime. Given that violent crime rates have been steadily increasing since 2014 (Allen, 2018), the costs and consequences of these type of crimes is further evidence for the breadth of the challenges that violence presents in Canada. It also serves to emphasize the importance of accurately measuring, forecasting, and preventing violent crime. 


\section{Measurement of Violence}

Violence can be defined as a sub-type of aggression, wherein the goal is to inflict extreme harm (Anderson \& Bushman, 2002; Bushman \& Anderson, 2001). This definition is often limited to physical acts (Tapscott \& Hoaken, 2014). Aggression, on the other hand, is defined more broadly as any behaviour directed at another individual that is meant to and believed by the perpetrator to inflict harm, and which the target is motivated to avoid. In addition to violent acts, this might include verbal or psychological assaults (Bushman \& Anderson, 2001; Walby et al., 2017).

Challenges of measuring violence: construct operationalization. There is a lack of consensus among organizations that address violence as to how this construct should be operationalized (Walby et al., 2017). Researchers and those who study violence often require more specific operationalizations of violence (e.g., by focusing on violence as specific physical acts, and the consequences on physical, mental, and sexual health). Other organizations opt for a more general operationalization of violence which more closely aligns with the definition of aggression, and includes a broader range of behaviours, motivations, and actions (Ruiz-Perez, Plazaola-Castano, \& Vives-Cases, 2007; Walby et al., 2017). These divergent operationalizations can result in inconsistent or flawed data, making it difficult to assess the usefulness of different tools for measuring violence across settings.

Challenges of measuring violence: sources of data. Self-report and formal record sources of data often diverge due to the general lack of formal 
reporting of violent crimes (Allen, 2018). This can lead to discordant findings on prevalence rates. Similarly, self-report measures can be limited by the very nature of the measure. Perpetrators may respond in a dishonest way when asked about their own perpetration of crimes (Mills \& Kroner, 2006), though recent research suggests this may not be the case, even when questions are offence or violence-specific (Kroner, Mills, \& Morgan, 2006; Mathie \& Wakeling, 2011). Police reports and criminal justice records may also only offer a limited source of information due to a lack of formal reporting (Walby et al., 2017), and information that is reported may be skewed by reporting errors or bias. These issues present a methodological challenge for studying violent crime, as it makes it difficult to ascertain base rates of violence, as well as compare results across measures and studies (Allen, 2018).

Challenges of measuring violence: base rates. In a similar vein, low base rates of violent offending and re-offending in many samples of offenders present a challenge to the study of violence (Grych \& Hamby, 2014). First, this can result in skewed data, which requires researchers to correct for this issue using statistical methods, such as transformations, which can lead to questions about inaccurate results and interpretations. Second, it might require increased observation and data collection time, which can become costly and ineffective, and this makes strong research methodologies like randomized control trials difficult to conduct. Third, an insufficient sample size may be collected to detect the effect, even if there is a true effect to be detected (Nunes et al., 2019).

Challenges of measuring violence: lab versus field studies. Research collected in lab versus clinical settings may also pose challenges to the study of violence. Both 
sides have traditionally been wary of the other, with questions arising about the usefulness of studies in one setting for application in others (Anderson \& Bushman, 1997; Anderson, Lindsay, \& Bushman, 1999). The tools used in lab studies of violent behaviour are ideal for ensuring high internal validity. However, they have been criticized for their lack of perceived convergence to "real world" violent behaviour, their general versus specific examination of aggression, and the difficulty with maintaining the deception necessary to maintain accuracy of these measures (Grych \& Hamby, 2014; Nunes et al., 2019; Ruiz-Perez et al., 2007). On the other hand, lab-based researchers have been skeptical of research conducted in applied forensic settings for their lack of experimental control (e.g., limited number of randomized control trials due to the challenges associated with low base rates of violence and long follow-up times for official sources of violent behaviour, as previously discussed; Nunes et al., 2019).

Therefore, while measurement of violence has improved in recent history (Grych \& Hamby, 2014), it is still important for researchers to have access to a valid measure of violence which may assist in mitigating these challenges. For this reason, Nunes and colleagues (2019) developed and initially validated the Violence Propensity Vignette Questionnaire (VPVQ). In particular, the VPVQ was developed with the aim of creating a measure of current propensity for violent behaviour that would allow for these related but different settings and contexts to measure violence in a similar, consistent, and comparable way. 


\section{The Violence Propensity Vignette Questionnaire (VPVQ)}

The VPVQ is a computer-administered self-report measure containing a series of ten vignettes depicting various confrontational situations. Respondents are asked to select, among nine possible responses, the one that most accurately reflects how they would react if they were currently in the described situation. Respondents are presented with an initial aggressive situation, and then, upon selecting a response, are presented a second scripted response from the aggressor. Participants are then asked to give a second response to the confrontation, selecting again from the same set of options. Participants' selections from the nine response options are coded dichotomously as either violent or non-violent for each vignette. A more detailed description of the VPVQ can be found in the Methods section, and the measure and response options can be found in Appendix A.

Development of the VPVQ. The development of the VPVQ occurred in several stages. First, interviews with incarcerated violent offenders and men in the community provided the basis for a pool of initial stories and the possible response options. They were asked to describe the circumstances surrounding instances of violence that they were part of, as well as antecedents and responses. The authors also utilized information from other questionnaires, analog measures, and role-play situations provided during research and treatment with violent offenders to craft a set of vignettes to be further evaluated for relevance and statistical viability.

Once an initial pool of vignettes was developed, the authors first presented them to a new sample of community males, students, and offenders, and solicited responses to the scenarios using open-ended questions. Base rates of violent responding for the 
vignettes were recorded to ensure that they reflected actual base rates of violence (i.e., that they were not too high or low, threatening construct and statistical validity as violence is a typically low base-rate event). The vignettes that elicited problematically low violent responding were dropped or modified to increase the measure's relevance. For example, vignettes depicting the respondent as committing intentional or premediated (i.e., proactive) violence were present among the original set of vignettes but were dropped due to unanimously low rates of violent responses in the open-ended questions. The vignettes were also presented alongside other self-report measures of violence, aggression, and recidivism to assess construct validity (Clark \& Watson, 1995, 2019).

The package of new vignettes and the self-report measures of violence were administered to a third, new sample of community males and offenders. The vignettes were presented in a randomized order alongside a series of forced-choice response options adapted from the responses to the previous validation phases. Base rates were recorded for each validation phase to ensure consistency across the samples (Nunes et al., 2019). Similar results were replicated in the third stage, and the final list of ten relevant vignettes culminated in what is now the VPVQ.

VPVQ validation with community men and male inmates. The VPVQ was presented to a new sample of community men online with the vignettes presented in a randomized order. Base rates of violent responding on the vignettes were recorded, and responses were again correlated with the currently utilized self-report measures of violent behaviour and aggressiveness (i.e., the Violent Behaviour Scale [VBS]; Nunes et al., 2015, and the Physical Aggression subscale of the Aggression Questionnaire [PA-AQ]; Buss \& Perry, 1992, respectively). For 
this sample, the base rates of violent responding ranged from roughly $15 \%$ (vignette $7:$ a guy is behind you in line at a store and keeps bumping you and being loud) to $51 \%$ (vignette 9: another guy tries to pick up your girlfriend at a bar while acting like you aren't even there). These base rates are in line with the 2017 Canadian violent crime rate (i.e., 21\%; Allen, 2018, p. 13) discussed previously, apart from vignette 9, for which the base rates are higher. However, given that these are the rates for the Canadian population rather than a sample of men exclusively, these rates should be used for illustrative purposes only, and considered with caution. They noted that those who selected violent responses to more vignettes on the VPVQ consistently reported more past self-reported violent behaviour and aggressiveness (Cohen's $d$ s ranged from 0.73 to 0.94 ; Nunes et al., 2019 , p. 22). Additionally, those who selected a violent response to at least one of any of the ten vignettes reported more past violent behaviour (Cohen's $d=0.80$ ) and aggressiveness (Cohen's $d=1.15$ ). VPVQ total score was highly correlated with selfreported violent behaviour $(r=.47)$ and physical aggressiveness $(r=.58$; Nunes et al., 2019, p. 60).

A similar pattern of results emerged when the authors presented the VPVQ to 52 inmates in medium and maximum-security prisons in Canada. Base rates for responding were good, ranging from roughly $10 \%$ (vignette 2: guy cuts in front of you in a long line) to $45 \%$ (vignette 9), and showed no indication of ceiling or floor effects. There were high correlations between violent behaviour and physical aggressiveness and violent responses on the VPVQ per vignette, further suggesting good construct validity. Overall violent rating on the VPVQ (i.e., selecting any violent option on any of the ten VPVQ vignettes) was also related to high rates of reported past violent behaviour $(r=.51)$ and physical 
aggressiveness ( $r=.74$; Nunes et al., 2019, p. 60). However, scores on the VPVQ were not consistently related to convictions $(r=-.02)$, though they were related to risk of violent re-offending. This was demonstrated by the VPVQ's moderate-tostrong relationship with the Self-Appraisal Questionnaire (SAQ, a self-report measure for predicting risk for violent reoffending; Loza, 1996 as described in Loza \& Green, 2003) but weak relationship with the Statistical Information of Recidivism (SIR; Nafekh \& Motiuk, 2002). Importantly, selecting at least one violent response to any of the ten vignettes on the VPVQ was related to risk for re-offending, though modestly.

These results are in line with previous research demonstrating that responses to self-report measures such as the VPVQ correspond with actual selfreported aggressive behaviours, and may incrementally predict antisocial and violent behaviour in both forensic and non-forensic samples (Hilton, Harris, \& Rice, 2003; Jones \& Miller, 2012; Piquero, Schubert, \& Brame, 2014). This further supports the suggestion that the VPVQ may be an accurate measure of violence. However, the dimensionality of the construct the VPVQ is measuring has yet to be examined. While the reactive-proactive dichotomy and evolutionary theories about males' response to status threat may serve to support unidimensionality of the VPVQ, other evolutionary psychological theories regarding relationship and sexual mating behaviours may suggest multidimensionality. 


\section{Dimensionality of the VPVQ}

Nunes and colleagues (2019) suggested that the VPVQ is a proxy for measuring violence (see the distinction between violence and aggression above). In the following section I will present evidence regarding male violence which might suggest uni- or multidimensionality of the VPVQ.

Evidence for possible unidimensionality: reactive vs proactive violence. In their original validation of the VPVQ, Nunes and colleagues (2019) posited that the measure might be assessing hostile/impulsive or reactive violence, but not instrumental/premeditated or proactive violence. In this way, the authors have suggested that the VPVQ is a unidimensional measure of violence. Reactive violence is usually unplanned and motivated by anger or other negative affect (Soothill, Rodgers, \& Dolan, 2008) as a response to a threat from a perceived provocation from another person. In contrast, instrumental or proactive violence is a more explicitly planned form of violence, used with the aim of obtaining some goal other than mere harm (Anderson \& Bushman, 2002).

These two forms of violence were recently demonstrated in a confirmatory factor analytic study of children's self and teacher-reported engagement in aggressive behaviour. Rieffe and colleagues (2016) had a group of children from primary schools in the Netherlands and their teachers complete the Instrument for Reactive and Proactive Aggression (Polman et al., 2009), indicating how frequently $(1=$ never to $5=$ very often $)$ they/their students had engaged in various reactive and proactive aggressive behaviours in the past four weeks. Using exploratory and confirmatory factor analytic methods, the authors demonstrated that the 2-factor structure had a good fit to both the teacher and 
self-reports, with measurement and scalar invariance (i.e., models testing the equivalent measurement of a construct across time or groups and intercept values, respectively) being established. The reactive and proactive items also formed distinct factors as hypothesized.

Many acts of violence are classified as reactive rather than proactive, as evidenced in the results of a study conducted by Stanford, Houston, Mathias, Villemarette-Pittman, Helfritz, and Conklin (2003), in which most sampled community men (90\%) were classified as impulsively violent (i.e., reactively violent) on the Impulsive/Premeditated Aggression Scale (IPAS; Stanford et al., 2003). Both reactive and proactive violence has also been demonstrated to be more prevalent among male offenders and community samples (Aydin \& Akgun, 2014; Euler, Stienlin, \& Stadler, 2017; Tapscott, Hancock, \& Hoaken, 2012), with reactive violence being more common than instrumental violence in community samples (Fite, Raine, Stouthamer-Loeber, Loeber, \& Pardini, 2010). Acts of reactive violence have also been demonstrated to be more severe than those of instrumental violence (Tapscott, Hancock, \& Hoaken, 2012), though there are some inconsistent findings on this (Ennis, Toop, Jung, \& Bois, 2017; Reidy, Shelley-Tremblay, \& Lilienfeld, 2011).

Reactive-proactive dichotomy and the VPVQ vignettes. The structure and content of the vignettes suggest that the VPVQ most likely assesses reactive rather than proactive violence. Each of the ten vignettes begins with an aggravating slight committed against the respondent, such as another guy hitting on their girlfriend in a bar as if they are not there. In each case, those responding 
to the vignettes are being asked to respond after the occurrence of the initial slight; in no instance is the respondent the primary aggressor. The goal of violence use is not premeditated (i.e., it only occurs as a response to the threat), and there is no goal other than to harm or eliminate the threat. In the aforementioned example, the respondent is not attacking any man he thinks might try to hit on his girlfriend; he is responding to eliminate the immediately occurring relational threat.

Relatedly, in the first stage of the development process for the vignettes, Nunes and colleagues (2019) had included scenarios in which the participants were depicted as displaying more proactive violence. However, as indicated, these vignettes were dropped from the VPVQ due to low endorsement rates of violent behaviour by participants for these events (Nunes et al., 2019). This would further be consistent with the assertion that the VPVQ is assessing reactive, but not proactive violence.

Evidence for unidimensionality: status threat. In addition to the reactive nature of the VPVQ vignettes, threats to status and threats of public humiliation may serve as evidence for the unidimensionality of the VPVQ. Anderson, Hildreth, and Howland (2015) noted in their review that reactive violent responses to threat were more likely to occur when the aggression took place in public, and that retention or protection of status was considered an acceptable reason for males to respond with aggression. This is important because in both rounds of responding to the aggressor in the VPVQ vignettes, the aggressor is threatening the target's perceived status. Torres and Bergner (2012) describe 'status' as the social position of the person in relation to the world around them (p. 493), and further describe that the person attempting to gain status can either present themselves as having that status, or have others grant it to them. They indicate that many 
measures, including violence, may be taken to subvert the threat to their status regardless of the source. This might support the case that, while the content of the VPVQ vignettes are all different, they may still be measuring a single construct of reactive violence propensity.

Relatedly, Chen (2015) demonstrated that even a small perceived humiliation (i.e., social status threat) could result in retaliatory aggression, and that this direct relationship was significant in a mediation analysis. When their participants received scripted rejection or criticism on a simulated social media platform, those who received any status-threatening responses from the simulated group members were more likely to retaliate by sending ticking bomb messages (i.e., aggressive messages) as compared to the control group who received affirmative messages. Importantly, there were no differences in aggressive responding to either the criticism or rejection threats. Extrapolating these findings to the vignettes of the VPVQ, this might further suggest that that the perceived threat to status may elicit violent responding in those who have a propensity for responding violently, regardless of the content or extent (i.e., criticism or full rejection) of the threat. In other words, the VPVQ would be measuring the single underlying construct of violence propensity, and thus present as unidimensional.

\section{Evidence for possible multidimensionality: sexual possession threat.}

While the authors of the VPVQ posit that the VPVQ is unidimensional, I am allowing for the possibility of multidimensionality to occur. Another theory posited in evolutionary psychology is that male violence may be more likely to occur as a result of "sexual possessiveness" or sexual jealousy (Wilson \& Daly, 
1998). These authors note that males may have evolved to be attuned, and more likely to respond violently to, threats to the sexual possession of "their women." They also speculate that violence as a result of this concern is likely to target the males who are initiating the perceived or real threat. For this reason, it is possible that those vignettes depicting intimate partner violence or perceived sexual threat from another man may factor differentially than other stranger-aggressor or acquaintance-aggressor vignettes. In other words, these vignettes may represent a second dimension of the VPVQ as compared to those which depict provocations from strangers or acquaintances.

Sexual protection threat. Similarly, sexual protection may play a differential role in males' violent responding to the VPVQ. Evidence for this phenomenon has been demonstrated in studies examining men's responses to perceived manhood threat. O'Dea, Chalman, Castro Bueno, and Saucier (2018) had males read vignettes where a male protagonist or his girlfriend was bumped on the shoulder while walking and insulted by an antagonist. They then measured the perception of the protagonist when he responded violently or not. They demonstrated that aggressive responding was considered positive in both scenarios. However, when the slight was committed against the protagonist's female partner, aggressive responding was perceived more positively than even aggressive responding to the slight against the protagonist. This might further suggest that the VPVQ vignettes that concern a threat to the man's wife or girlfriend or their relationship (e.g., the vignettes depicting another man referring to the participant's girlfriend as a slut) may factor separately from other vignettes because it is considered more accepted or necessary to respond violently to protect a female. 


\section{Is the VPVQ Distinct from Other Measures of Aggression or Violence?}

Following the development of the VPVQ, the authors began the preliminary validation process (Nunes et al., 2019). Specifically, the authors examined the relationship between the VPVQ and the Physical Aggression subscale of the Aggression Questionnaire (PA-AQ; Buss \& Perry, 1992; see Appendix B), as well as the Violent Behaviour Scale (VBS; Nunes et al., 2015; see Appendix C) and other measures of violent offending and recidivism. This is important, as construct validity evaluation must be informed by previous research and theory to successfully demonstrate that the new measure can accurately measure similar constructs in meaningfully similar ways (Clark \& Watson, 1995, 2019; Peterson, 2017). According to Clark and Watson (1995), it is equally important that a valid assessment measure be distinct from existing measures, upon which I am basing the second research question of this study.

PA-AQ. One of the measures that Nunes and colleagues (2019) used in their validation of the VPVQ was the PA-AQ. The original AQ was developed by Buss and Perry in 1992 and was adapted from an earlier version: the Buss-Durkee Hostility Inventory (BDHI; Buss \& Durkee, 1957). The AQ has four sub-scales: Physical Aggression (PA), Verbal Aggression (VA), Anger, and Hostility. As Gerevich, Bacskai, and Czobor (2007) pointed out, the four facets of the AQ have become the most widespread measure used to assess aggression. Use of the PA-AQ as a comparative measure for the VPVQ in the initial and current studies was due to the prolific use that this measure and its various forms (e.g., a shortened version by Bryant and Smith [2001]; see McKay, Perry, \& Harvey [2016] for another discussion) has in aggression research and practice (Reyna, Ivacevich, Sanchez, \& Brussino, 2011). 
VBS. The VBS was also used in the original VPVQ validation studies. The VBS was created in 2015 by Nunes and colleagues (2015). It is a self-report measure of violent behaviour and criminal justice involvement, with eight items asking participants to rate the number of times they have been involved in such behaviours since the age of 16 . This measure was created by combining modified versions of select items from other antisocial behaviour scales, adding items addressing arrest and conviction, and generating a numerical response scale. More information about the psychometric properties of both measures can be found in the Method section.

How might the VPVQ be unique from these measures? The diversity of the source information for the development of the VPVQ might set it apart from other measures of violence. According to Buss, Durkee, and Baer (1956), the initial development of the components of the BDHI (i.e., the predecessor of the AQ) were derived only from clinical rating of various aspects of hostility of patients at a neuropsychiatric hospital, rather than using a community sample. The development of this measure, as well as the later AQ, required that items use idioms that reflected everyday speech due to their more common use in everyday language, and "borrowed items from other inventories" (Buss \& Durkee, 1957, p. 344). However, the authors did not expand to include any interviews with community males for the AQ, nor did they specify from which measures they borrowed items. Similarly, the VBS was developed using only items from other measures of violence and criminality. While some aspects of the AQ and VBS' development mirrors the development process of the VPVQ, the more expansive source information may contribute to its uniqueness, as well as its applicability to diverse populations. 
Additionally, unlike other self-report measures of violence and aggression, the VPVQ relies on participants' responses to an imagined presently occurring instigation. This contrasts with other measures that rely on the respondents' reflection and reporting on past behaviour and extrapolating about how that might equate to current propensity. The instructions for the VPVQ ask the participant to "[...] say what you would really do if you were in that situation right now" (Nunes et al., 2019, p. 20). This would, presumably, suggest a more accurate forecast of propensity for current situational violence than self-reported reflection on past behaviour. This may be because the VPVQ items are temporally more consistent as compared to the re-call necessity of the AQ and VBS, and the immediacy of the situation is more realistic.

\section{The Current Study}

The aim of the current study was to explore the underlying factor structure of the VPVQ vignettes and the response options, as well as examine the distinctiveness of the measure with other currently utilized measures for assessing violence and aggression. Nunes and colleagues (2019) suggested that the items of the VPVQ would emerge as unidimensional, and that it is only measuring reactive and not proactive violence. In the pre-VPVQ vignette development stage, the authors had included vignettes depicting proactive violence, but these were dropped before the VPVQ development was completed due to low endorsement. The VPVQ vignettes all depict an initial aggression against the participant, to which they must react. The participant is never the initial aggressor. It was posited that, for these reasons, the VPVQ vignettes should not require more than a 1factor structure, because they should be measuring a similar underlying construct. 
However, evidence from other fields of study such as evolutionary psychology suggests that the VPVQ might present with a multidimensional structure. It is possible that the vignettes depicting incidents of intimate partner violence or threats to a man's partner or relationship status may factor differentially from the stranger or acquaintance vignettes. This may be as a result of sexual status threat response, or sexual protection responses which may have a different impact on men than provocation from a stranger or acquaintance unto themselves. Due to the exploratory nature of this study, I did not propose any specific hypotheses regarding the emergent factor structure (Flora, LaBrish, \& Chalmers, 2012).

Concerning the distinctiveness, I was interested in testing the extent to which the VPVQ items factor separately from the items on the other measures. Specifically, I was interested in the extent to which the VPVQ did not factor separately from the other measures. This outcome would suggest that the VPVQ is not a distinct measure of violence, but merely redundant with its comparison measures. On the other hand, if the VPVQ did factor separately from the other measures, this may suggest that the VPVQ is non-redundant. However, it may also be that the factor structure outcome might be influenced by extraneous information, such as the measurement format or cognitive load (Goldberg \& Velicer, 2006).

If the VPVQ items factored separately, a supplementary regression analysis was to be conducted to examine the extent to which there was a unique association between the VPVQ and the other measures. If the VPVQ vignettes factored separately from the PA-AQ and VBS items, and the VPVQ had a unique association with responding on the other measures, this would provide stronger evidence that the VPVQ is not simply a 
redundant measure, but a measure of a distinct construct. In their original validation, Nunes and colleagues (2019) were successful at demonstrating that the three measures were related in a meaningful way. My study aimed to take this a step further, investigating the extent to which the items of the VPVQ are related but distinct from one another.

Finally, I also conducted a secondary, exploratory examination of the underlying structure of the VPVQ response options (i.e., the 9 response options that participants can select as responses to the provocation). As with the previous research questions, I did not propose any specific hypotheses for this analysis.

\section{Methods}

\section{Participants}

Secondary data analyses were conducted on the community sample data collected in the original Nunes and colleagues' (2019) study 3 . The community sample was a group of 471 adult males who self-reported as having heterosexual orientation, understood written English, answered the appropriate number of questions from each of the scales, and correctly answered the quality control items. Their mean age was 36.98 years old $(S D=13.54)$, with a range from $18-81$ years. The majority were married $(46.3 \%)$ or single $(28.9 \%)$. They were recruited via an online Qualtrics panel. For this study, I used the community sample from study 3 only. While I would have liked to include the offender sample from study 4, EFA requires a large sample size (i.e., more than 300 responses) to prevent over-factoring, as well as to produce a factor structure which is stable, and prevent the emergence of Heywood cases (i.e., factor loadings greater than 1; 
Costello \& Osborne, 2005; McNeish, 2016). The original offender sample did not attain this minimum. Data collection for the Nunes and colleagues (2019) study took place in 2015 .

\section{Measures}

VPVQ. The VPVQ (Nunes et al., 2019) is a computer-administered self-report measure consisting of 10 vignettes depicting provocative conflict situations. For example, respondents may be told they are at a bar with their girlfriend, and another man begins hitting on their girlfriend in front of them as if they were not there. Each vignette is presented in two rounds: an initial provocation to which the participant responds, and then a scripted retaliation from the aggressor to the respondent's initial decision with a second response from the participant. Respondents are asked "What would you do?" and then presented the initial provocative vignette. Hilton, Harris, and Rice (2003) demonstrated that responses to scenario-based self-report measures such as the VPVQ correspond with actual self-reported aggressive behaviour in similar real-world situations.

There are a total of nine possible response options, which are coded dichotomously as violent (i.e., "shove him", "hit, punch, kick, or tackle him" "threaten to hurt him"; Nunes et al., 2019, p. 20) or non-violent (i.e., "report it to someone”, "talk it out", "ignore it", "leave," "joke about it", "insult him"; p. 21). Once participants respond, they are then presented with the aggressor's retaliation, and asked to respond a second time using the same options. The vignettes are presented in a random order. As described in the introduction section, the vignettes and possible responses were adapted from real stories that Nunes and colleagues collected from male offenders and community members, as well as stories from clinical role-plays and analogs. Internal 
consistency for the VPVQ total score in study 3 was good (Cronbach's $\alpha=.82$; Nunes et al., 2019).

The PA-AQ. The PA-AQ (Buss \& Perry, 1992) is a 9-item subscale of the Aggression Questionnaire which measures physical aggression. Participants respond to 5point Likert-style statements, ranging from 1 (extremely uncharacteristic of me) to 5 (very characteristic of me). The subscale score is computed by summing the total of the responses to each item, with a range of $0-45$. For the original Nunes and colleagues' (2019) and current studies, the total score of this sub-scale was computed by averaging the scores of all nine items and can range from 1 to 5 (Nunes et al., 2019). Internal consistency for the community sample in study 3 was good (Cronbach's $\alpha=.80$; Nunes et al., 2019). Exploratory and confirmatory factor analysis (EFA and CFA) procedures have demonstrated that the PA subscale factor most consistently emerged when conditions such as sample size, age, and item inclusion/exclusion were considered, and that this subscale had the most discriminatory power compared to the other three (Gerevich, Bacskai, \& Czobor, 2007). This indicates that this subscale is appropriate to use as a comparison measure for the VPVQ.

The PA-AQ has also demonstrated good reliability and validity when examined in a series of studies by Webster and colleagues (2015). In studies 1 and 2, Webster and colleagues demonstrated that the PA items loaded strongly on the PA factor (factor loadings between .60 and .98; study 1), and that the PA subscale had high latent testretest reliability correlation $(r=.88)$. In study 3 , they demonstrated that the 4 -factor structure for the AQ had the best fit to the data in a non-student sample, with metric and scalar invariance models consistently demonstrating good fit compared to unidimensional 
and hierarchical models. When Buss and Perry (1992) examined the association between self-reported responses to the PA-AQ with peer nominations of aggressive behaviour, this correlation was the strongest of the four subscales $(r=.45$ for the PA-AQ, compared to $r \mathrm{~s}$ $=.20-.30$ for the other scales). Other studies have demonstrated that the PA subscale accounted for the greatest proportion of explained variance $(23.64 \%$ compared to $7.86 \%$ [verbal aggression], 4.99\% [anger] and 4.18\% [hostility]; Santisteban, Alvarado, \& Recio, 2007, p. 1456).

VBS. The VBS was included in the initial validation process and, as such, was included in the current factor analysis. Internal consistency for this measure in Nunes and colleagues' (2019) study 3 with the community sample was good (Cronbach's $\alpha=.81$ ), and "similar self-report measures have been demonstrated to be associated with criminal justice indicators of antisocial behaviour" (Nunes et al., 2019 p. 11; Thornberry \& Krohn, 2000). This scale consists of eight self-report items for which the respondent must declare their frequency of engaging in past criminal and antisocial behaviours (e.g., "From when you were 16 years old to today, how many times have you been arrested for a violent offense?"). Response options range from 0 (never) to 9 (9 times or more), and the total score can range from 0-72. Like the PA-AQ, the total score of this measure is typically computed by summing the responses for each of the eight items, but the authors of the Nunes and colleagues (2019) study and I again used the mean scores for the VBS. Therefore, for the current study, the VBS had a total range of 0-9.

The construct validity of the VBS has not yet been explicitly tested using other measures of violent behaviour. As such, this lack of construct validity evidence might call into question whether the VBS is an adequate comparison measure. However, some 
research suggests that measures that assess uniquely behavioural outcomes, as does the VBS, tend to exhibit higher rates of validity evidence (see Walby et al., 2017). This would suggest that the VBS should be a valid comparison measure for this study.

\section{Statistical Analyses}

EFAs were conducted on the community sample dataset from the original Nunes and colleagues (2019) study. My current statistical analyses closely followed a similar, earlier EFA procedure conducted by Nunes, Hermann, White, Pettersen, and Bumby (2018). Factor analysis is a useful analytic tool that can serve to determine how many latent factors underlie a set of items and help elucidate potential common themes among a set of items (Devellis, 2017). EFA is more lenient than CFA, allowing for cross-loading of the items into several factors. Rather than making definitive statements about the latent structure of a construct or constructs, EFA assesses dimensions of shared variance among specific items in order to generate hypotheses about or identify the underlying latent structure (Bendalos \& Finney, 2010; Smith, McCarthy, \& Zapolski, 2009; Tabachnick \& Fidell, 2013). EFA is the preferred method in initial exploratory validation, when the underlying structure of a measure is not previously understood, such as is the case in my study.

Two separate EFAs were conducted to examine the factor structure and distinctiveness of the VPVQ, using MPlus 8.1 (Muthén \& Muthén, 2018). For each of the EFAs, I coded each of the response options for the VPVQ vignettes dichotomously, with 0 representing the selection of a non-violent option, and 1 representing the selection of a violent option. This was consistent with the 
authors' original coding in the VPVQ's validation study. This means that if a respondent selected a violent option for either of the two rounds of each vignette (i.e., after the initial instigation or the retaliation phase of each vignette), they received a score of 1 for that vignette. If they selected a non-violent option for both phases of the vignette, they received a 0 for that vignette. For example, if a participant selected "joke about it" after the initial instigation phase, and then selected the response option "hit, punch, kick, or tackle him" after the retaliation phase of vignette 1, vignette 1 would get an overall score of 1 . If, for vignette 2, a participant selected "leave" for both phases of vignette 2 , then vignette 2 would get an overall score of 0 . Importantly, in the case of missing data on one of the two vignette response phases and selection of a non-violent response for the other (e.g., if after the instigation, a participant selected "ignore it" and the post-retaliation response was missing), this was not considered sufficient information to definitively code that vignette as a 0 , and instead was given a designation of missing (coded as 9999).

Factors were extracted from polychoric correlation matrices due to the dichotomous nature of the data (Holgado-Tello, Chacon-Moscoso, Barbero-Gracia, \& Vila-Abad, 2010) after checking for issues with multicollinearity between any of the independent variables or factorability of the data (i.e., the appropriateness of using EFA for the data; Watson, 2017; Williams, Onsman, \& Brown, 2010). For this, I considered interitem correlations between .30 and .90 to be adequate for the data to be considered factorable and free of multicollinearity (Watson, 2017; Williams, Onsman, \& Brown, 2010). While none of the correlations exceeded .90 , indicating no problems with multicollinearity, a few correlations in the distinctiveness EFA fell below .30. Therefore, I conducted the EFA procedure with these items included and excluded (Flora, LaBrish, 
\& Chalmers, 2012). Factor extraction was done using the Weighted Least Squares estimator (WLSMV), with factor loadings greater than .40 being considered for factor loading (Nunes et al., 2018). Factors were rotated using an oblique rotation (Geomin) because it most closely approximates a simple and stable structure with correlated factors (Sass \& Schmitt, 2010, p. 90). These models were first run using 1000 iterations, but then were increased to 5000 iterations where model convergence was not achieved in 1000 iterations.

Multiple methods were used for factor extraction, as recommended, including scree plot, Kaiser's rule, Velicer's Minimum Average Partial test (MAP), and Parallel Analysis (Devellis, 2017; Ledesma \& Valero-Mora, 2007; Reio Jr. \& Shuck, 2015). This was done to account for the shortcomings of each method. Kaiser's Rule (i.e., retaining factors with eigenvalues greater than 1) tends to overfactor, as evidenced in Reyna and colleagues (2011). They noted that Kaiser's rule produced eight factors, while scree plot and Parallel Analysis produced only four for the AQ. Scree plots may lack distinct “elbows," making it unclear how many factors are being suggested (Reio Jr. \& Shuck, 2015). When conducting analyses with categorical data, MAP analyses perform better with polychoric correlation matrices and larger sample sizes (i.e., projected sample sizes of roughly 500) according to Monte Carlo simulations (Garrido, Abad, \& Pondosa, 2011). Because I used polychoric correlation matrices, and Nunes and colleagues' (2019) community sample consists of just under 500 participants, results of the MAP analysis were considered preferentially in the event of discrepancies between the various indices. Importantly, however, both MAP and Parallel Analysis were considered in order to 
account for the tendency of each test to over- and underfactor, respectively, when using oblique rotation methods (Caron, 2018).

Finally, I also used multiple methods for determining the model fit. As suggested by Bentler in Schmitt (2011), I report fit indices using three different metrics: Standardized Root Mean Square Residuals (SRMR), Root Mean Square Error of Approximation (RMSEA), and Comparative Fit Indices (CFI). Though there is some contention as to what cut-off values should be used, and discretion and attention to the research question is suggested in selecting these (see Schmitt [2011] for a more thorough discussion), the following cut-offs were used for the model fit to be considered adequate: RMSEA should not exceed 0.06 , CFI equal to or exceeding 0.95 , and SRMR should not exceed 0.08 (Schmitt, 2011).

Supplemental analysis: regression. As previously indicated, the results of the distinctiveness EFA provided information regarding the redundancy of the VPVQ with other measures only insofar as not factoring separately indicates redundancy. However, the reverse is not necessarily true. The measures may factor separately due to issues unrelated to the constructs that each is measuring. For example, the different response modes for each of the measures (i.e., counts on the VBS versus a Likert scale for the PAAQ versus selecting a hypothetical response on the VPVQ) can result in the items factoring separately, regardless whether they measure distinct or overlapping constructs.

As such, I conducted a follow-up hierarchical regression analysis on the factor and mean scores of the three measures with the aim of examining the unique association of the VPVQ with VBS and PA-AQ scores. If the VPVQ is non-redundant, then I expected that, in addition to the VPVQ items factoring separately from the items from the 
other measures in the EFA, that the VPVQ would have a unique association with responding on these measures, while holding the effects of the other measures constant. Taken together, these results would suggest that the VPVQ should be represented by a separate underlying construct than the other two measures, and that what is being measured by the VPVQ is unique information that is not already being assessed by the other measures. Semi-partial and squared semi-partial correlations and $R^{2}$ change for each step were examined to determine whether there was an independent association for each measure.

Supplemental analysis: response options EFA. I also conducted a third EFA examining participants' transposed data from the vignette response options. This was done in a variety of ways. First, I dichotomized participants' raw response option selection, so that the data reflected whether participants selected a specific response option for any of the vignettes. For example, when creating a dichotomized variable for "hit/punch/kick/tackle him", that dichotomized variable was coded as 1 if, at any point, a participant selected this option. This variable was coded as 0 if they did not. Then, I conducted an EFA on these dichotomized variables, using the abovementioned decision rules and criteria. This analysis was conducted with the intention of exploring the latent factor structure of the VPVQ response options.

Due to the purely exploratory nature of this analysis, I also conducted an EFA on a set of continuous variables I derived to count the number of times a participant selected a specific response option across their two trials of each vignette. This means that they would receive a count of 1 for a vignette if, across either of their two selections, they selected a specific response option. In the case 
where a non-violent and a violent response were chosen for a given vignette, priority was given to coding the violent response. The range of these continuous variables was $0-10$. However, the extreme skewness of this variable was problematic due to the disproportionate amount of zero counts.

Instead, I derived a second count variable which simply counted how many times a participant selected a specific response option for each of their 20 responses to the VPVQ. This was different than the previous attempt in that participants would receive two points for a vignette if they had selected the same specific response for both choices and did not control for the dependence of the two choices. This choice was made because while the second provocation that participants received was dependent on their response to the first, they always had the option to select any of the nine response options. The range of possible scores for each participant, then, was 0-20. Descriptive information for each of the response option variables can be found in Appendix E. No issues with skewness were found, though three of the variables, "report it", "joke about it," and "leave" had a slightly high kurtosis.

Due to the continuous nature of this data, the parameters for this EFA were slightly different. This EFA used a Maximum Likelihood (ML) estimator with an oblique (Oblimin) rotation. RMSEA, SRMR, and CFI were again used to estimate model fit, and the same threshold values were used, given that they have been established as effective thresholds for continuous data (Schmitt, 2011). Kaiser's Rule, Scree plot, MAP, and Parallel Analysis were again to be used for factor extraction. However, I was unable to attain successful convergence on a properly fitted model for this analysis, and the 
interitem correlations suggested problems with the factorability of this data, as discussed more thoroughly in the Results and Discussion sections.

\section{Results}

Pearson correlations were computed for the mean scores of each of the measures included in the three EFAs. Skewness and kurtosis estimates for the VBS (skewness $=1.78, S E=.11$; kurtosis $=2.80, S E=.23)$ and VPVQ (skewness $=0.61, S E=.11$; kurtosis $=-0.65, S E=.23)$ demonstrated the need for bootstrapped confidence intervals for the correlations. Skewness and kurtosis for the PA-AQ was within an acceptable range, though bootstrapped confidence intervals were employed for consistency (skewness $=0.38, S E=.11$; kurtosis $=$ $0.43, S E=.23)$. The VPVQ was strongly positively correlated with the PA-AQ ( $r$ $=.57,95 \% \mathrm{CI}[.51, .64], p<.01)$, and moderately correlated with the VBS $(r=$ $.47,95 \% \mathrm{CI}[.37, .55], p<.01)$, such that more violent responding on the VPVQ was positively related with more self-reported endorsement of aggression and violent behaviour. The VBS and PA-AQ were also strongly positively correlated $(r=.55,95 \%$ CI $[.48, .62], p<.01)$.

\section{Underlying Factor Structure of the VPVQ Vignettes}

The first EFA was conducted to examine the underlying factor structure of the VPVQ. This EFA was conducted using WLSMV estimator from a polychoric sample correlation matrix and rotated using oblique rotation. The correlations for each of the vignette items can be found in Table 1, though all were in the appropriate range indicated above, suggesting no multicollinearity issues and that the matrix was factorable. The estimated number of factors to be retained for this 
EFA was between 1 and 3. Kaiser's criterion, Scree plot (see Figure 1), and MAP suggested a 1-factor structure, while the Parallel Analysis generally suggested 2 to 3 factors. The 1-factor structure was selected due to the parsimony and good fit to the data with an RMSEA of .042, 95\% CI [.025, .059], a CFI of .986, and a SRMR of .065. The eigenvalue for the retained factor was 5.69, with a proportion of explained variance (for the unrotated model) of .57. The rotated factor loadings of the VPVQ vignettes for the 1-factor model can be found in Table 2.

Interestingly, while the 1-factor structure was the most parsimonious, the rotated loadings of the 2-factor model (eigenvalue $=0.98$; variance explained $=.098 ;$ RMSEA $=$ $.013,95 \%$ CI $[.001, .04] ; \mathrm{CFI}=.999 ; \mathrm{SRMR}=.038$; factor correlation $=.63)$ suggested a tendency for the vignettes depicting instigation against a female to factor distinctly from the other vignettes. The factor loadings for this EFA can be found in Table 3.

Table 1.

Polychoric Correlations Between the Dichotomized Vignette Responses $(n=452)$

\begin{tabular}{lllllllllll}
\hline Vignette & 1 & 2 & 3 & 4 & 5 & 6 & 7 & 8 & 9 & 10 \\
\hline 1 & - & & & & & & & & & \\
2 & .60 & - & & & & & & & & \\
3 & .57 & .48 & - & & & & & & & \\
4 & .61 & .47 & .62 & - & & & & & & \\
5 & .54 & .48 & .62 & .60 & - & & & & & \\
6 & .54 & .42 & .49 & .40 & .57 & - & & & & \\
7 & .61 & .54 & .59 & .50 & .51 & .40 & - & & & \\
8 & .42 & .35 & .32 & .41 & .50 & .59 & .31 & - & & \\
9 & .51 & .56 & .54 & .61 & .60 & .59 & .43 & .58 & - & \\
10 & .60 & .51 & .53 & .53 & .69 & .51 & .55 & .38 & .57 & - \\
\hline
\end{tabular}

Note. None of the correlations fell below .30 or above .90 . Therefore, there were no issues with factorability or multicollinearity. 
Table 2.

Factor Loadings for Exploratory Factor Analysis with Oblique Rotation of VPVQ Vignettes (1-Factor)

\begin{tabular}{lc}
\hline Item & $\begin{array}{c}\text { Rotated factor } \\
\text { loading }\end{array}$ \\
\hline VPVQ Vignette 1 - Obnoxious roommate & $.77 \dagger$ \\
VPVQ Vignette 2 - Line cutter (guy cuts in front of you in a long line at the & $.68 \dagger$ \\
store) & \\
VPVQ Vignette 3 - Beer bump (guy dumps beer on you and calls you out \\
for being in the way) \\
VPVQ Vignette 4 - Beer run (guy takes your money to buy you beer, but \\
doesn't bring back your beer or money) \\
VPVQ Vignette 5 - Threat (guy walks up to you at a party and threatens \\
you) \\
VPVQ Vignette 6 - Unwanted guest (guy at a party harassing the hostess) \\
VPVQ Vignette 7 - Obnoxious guy in line (guy is speaking loudly and \\
rudely behind you, keeps bumping you with his arms) \\
VPVQ Vignette 8 - Intimate partner violence (you see a guy yelling at his \\
girlfriend, calling her names, and hit her) \\
VPVQ Vignette 9 - Interloper (guy puts his arm around your girlfriend/wife \\
and acts like you aren't even there) \\
VPVQ Vignette 10 - Disrespecting your girlfriend/wife \\
\hline $\begin{array}{l}\text { Note. '†' denotes factor loadings greater than .40. Unstandardized factor loadings are provided } \\
\text { due to the dichotomous nature of the data, and the use of oblique rotation. }\end{array}$
\end{tabular}


Table 3.

Factor Loadings for Exploratory Factor Analysis with Oblique Rotation of the VPVQ (2Factor)

\begin{tabular}{|c|c|c|}
\hline \multirow[b]{2}{*}{ Item } & \multicolumn{2}{|c|}{$\begin{array}{l}\text { Rotated factor } \\
\text { loadings }\end{array}$} \\
\hline & Factor 1 & Factor 2 \\
\hline VPVQ Vignette 1 - Obnoxious roommate & $.78 \dagger$ & .0001 \\
\hline $\begin{array}{l}\text { VPVQ Vignette } 2 \text { - Line cutter (guy cuts in front of you in a } \\
\text { long line at the store) }\end{array}$ & $.69 \dagger$ & .006 \\
\hline $\begin{array}{l}\text { VPVQ Vignette } 3 \text { - Beer bump (guy dumps beer on you and } \\
\text { calls you out for being in the way) }\end{array}$ & $.81 \dagger$ & -.07 \\
\hline $\begin{array}{l}\text { VPVQ Vignette } 4 \text { - Beer run (guy takes your money to buy } \\
\text { you beer, but doesn't bring back your beer or money) }\end{array}$ & $.72 \dagger$ & .05 \\
\hline $\begin{array}{l}\text { VPVQ Vignette } 5 \text { - Threat (guy walks up to you at a party } \\
\text { and threatens you) }\end{array}$ & $.64 \dagger$ & .23 \\
\hline $\begin{array}{l}\text { VPVQ Vignette } 6 \text { - Unwanted guest (guy at a party harassing } \\
\text { the hostess) }\end{array}$ & .29 & $.55 \dagger$ \\
\hline $\begin{array}{l}\text { VPVQ Vignette } 7 \text { - Obnoxious guy in line (guy is speaking } \\
\text { loudly and rudely behind you, keeps bumping you with his } \\
\text { arms) }\end{array}$ & $.87 \dagger$ & -.21 \\
\hline $\begin{array}{l}\text { VPVQ Vignette } 8 \text { - Intimate partner violence (you see a guy } \\
\text { yelling at his girlfriend, calling her names, and hit her) }\end{array}$ & .0001 & $.81 \dagger$ \\
\hline $\begin{array}{l}\text { VPVQ Vignette } 9 \text { - Interloper (guy puts his arm around your } \\
\text { girlfriend/wife and acts like you aren't even there) }\end{array}$ & $.45 \dagger$ & $.43 \dagger$ \\
\hline VPVQ Vignette 10 - Disrespecting your girlfriend/wife & $.71 \dagger$ & .09 \\
\hline
\end{tabular}

Note. ' $\uparrow$ ' denotes factor loadings greater than .40. Unstandardized factor loadings are provided due to the dichotomous nature of the data, and the use of oblique rotation. 


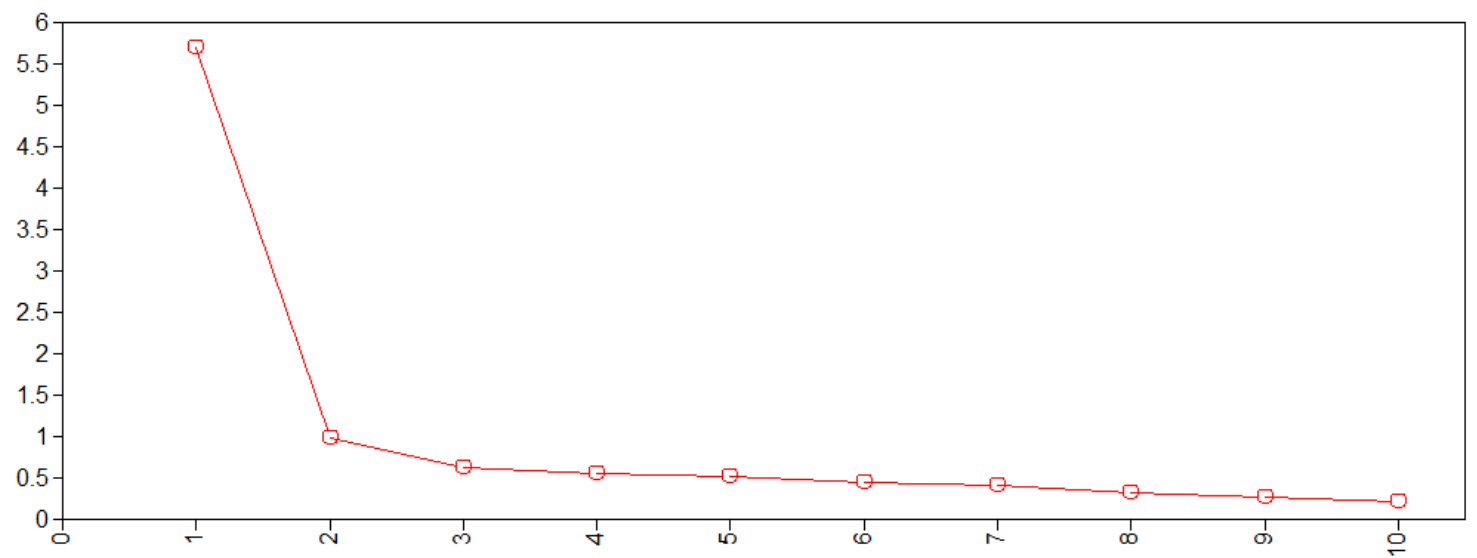

Figure 1. Scree plot for exploratory factor analyses of the VPVQ vignettes. The Y axis indicates the eigenvalues for the proposed factors, and the $\mathrm{X}$ axis indicates the number of extracted factors.

\section{Distinctiveness of the VPVQ from other Measures}

The second EFA was conducted to examine whether the VPVQ items factored separately from the PA-AQ and the VBS. The WLSMV estimator from a polychoric sample correlation matrix and oblique rotation were again used. The correlations for each of the items from the three measures can be found in Table 4. None of the correlations exceeded .90, indicating no multicollinearity issues. Importantly, however, the PAS7 and VBS4, VBS5, VBS7, and VBS8 item correlations were consistently less than .30, so this EFA was conducted with and without these items included. Including or excluding the items did not change the results dramatically, therefore I report on the results of the EFA with these items included for interpretational clarity.

The estimated number of factors to be retained for this EFA was between 3 and 9. Scree plot (see Figure 2) and the MAP analyses suggested fewer factors, with Scree plot suggesting 3 factors, and the MAP analysis suggesting 4 factors. 
Conversely, Kaiser's rule and Parallel Analyses suggested more factors, with Kaiser's rule suggesting 6 factors, and Parallel Analysis generally suggesting 5 to 9 factors. The 3factor structure was selected due to the parsimony and good fit to the data with an RMSEA of $.052,95 \%$ CI [.046, .058], a CFI of .965 and a SRMR of .071, with the items of the VPVQ, PA-AQ, and the VBS generally making up the three factors. The 4-factor structure proposed by the MAP analysis would also have been a good fit to the data $(\mathrm{RMSEA}=.041,95 \% \mathrm{CI}=[.034, .047] ; \mathrm{CFI}=.980 ; \mathrm{SRMR}=.054)$, but this factor structure was not considered to be parsimonious enough to adequately answer my research question, as this seemed to suggest item-level differences, but I was only interested in measure-level differences. The eigenvalues for the three retained factors were 11.02 for the VPVQ factor, 3.18 for the PA-AQ factor, and 1.75 for the VBS factor. The VPVQ factor was highly correlated with the PA-AQ factor $(r=.53, p<.05)$, and moderately correlated with the VBS factor $(r=.37, p<.05)$. The PA-AQ and VBS factors were also moderately correlated $(r=.47, p<.05)$. Estimated variance explained for the retained factors could not be calculated due to the presence of negative eigenvalues. The rotated factor loadings for each item of the three scales can be found in Table 5. As hypothesized, the VPVQ vignettes factored separately from the PA-AQ and VBS items, indicating a need to further examine the extent to which the VPVQ was unique from the other measures.

Follow-up hierarchical regression analyses were conducted to examine whether violent responding on the VPVQ was independently associated with responding on the PA-AQ and VBS. This was to supplement the results of the EFA analysis by examining whether the VPVQ was contributing unique information that was note entirely explained 
by one of the other measures. These analyses were conducted on both the factor scores generated from the EFA correlation matrix, and the mean scores of the three measures. Due to the high degree of skewness in the VBS and VPVQ scores, bootstrapped confidence intervals for the regression coefficients are reported (Wright \& Harrington, 2011). Because results of the factor score and mean score regression analyses converge on the same conclusion, I discuss the results of the mean scores only, though the results of the factor score analyses can be found in Tables 8 and 9. Selecting more violent responses on the VPVQ was independently related to increased aggressive and violent responding on both the PA-AQ and VBS, as demonstrated in Tables 6 and 7, respectively. The semipartial correlations suggest that the independent relationship with the VPVQ is small to moderate for both measures, with Step 2 of the regression analysis (with both measures included) demonstrating a significant change in $R^{2}$, regardless which measure was included first in the analysis. The squared semi-partial correlations further demonstrate the small unique contribution of the VPVQ. Taken together, these results demonstrate that the VPVQ has a small but unique association with responding on the PA-AQ, and VBS, suggesting that there is an aspect of participant responding on these measures that is uniquely assessed by the VPVQ. 
Table 4. Polychoric Correlations Between the Items of the VPVQ, PA-AQ, and VBS $(n=434)$

\begin{tabular}{|c|c|c|c|c|c|c|c|c|c|c|c|c|c|c|c|c|c|c|c|c|c|c|c|c|c|c|c|}
\hline & \multicolumn{10}{|c|}{ VPVQ } & \multicolumn{9}{|c|}{ PA-AQ } & \multicolumn{8}{|c|}{ VBS } \\
\hline & 1 & 2 & 3 & 4 & 5 & 6 & 7 & 8 & 9 & 10 & 1 & 2 & 3 & 4 & 5 & 6 & 7 & 8 & 9 & 1 & 2 & 3 & 4 & 5 & 6 & 7 & 8 \\
\hline \multicolumn{28}{|c|}{ VPVQ } \\
\hline 1 & - & & & & & & & & & & & & & & & & & & & & & & & & & & \\
\hline 2 & .60 & - & & & & & & & & & & & & & & & & & & & & & & & & & \\
\hline 3 & .57 & .48 & - & & & & & & & & & & & & & & & & & & & & & & & & \\
\hline 4 & .61 & .47 & .62 & - & & & & & & & & & & & & & & & & & & & & & & & \\
\hline 5 & .54 & .48 & .62 & .60 & - & & & & & & & & & & & & & & & & & & & & & & \\
\hline 6 & .54 & .42 & .49 & .40 & .57 & - & & & & & & & & & & & & & & & & & & & & & \\
\hline 7 & .61 & .54 & .59 & .50 & .51 & .40 & - & & & & & & & & & & & & & & & & & & & & \\
\hline 8 & .42 & .35 & .32 & .41 & .50 & .59 & .31 & - & & & & & & & & & & & & & & & & & & & \\
\hline 9 & .51 & .56 & .54 & .61 & .60 & .59 & .43 & .58 & - & & & & & & & & & & & & & & & & & & \\
\hline 10 & .60 & .51 & .53 & .53 & .69 & .51 & .55 & .38 & .57 & - & & & & & & & & & & & & & & & & & \\
\hline \multicolumn{28}{|c|}{$\begin{array}{l}\text { PA- } \\
\text { AQ }\end{array}$} \\
\hline 1 & .25 & .31 & .25 & .32 & .31 & .22 & .32 & .21 & .28 & .26 & - & & & & & & & & & & & & & & & & \\
\hline 2 & .45 & .32 & .35 & .50 & .49 & .42 & .35 & .42 & .49 & .44 & .56 & - & & & & & & & & & & & & & & & \\
\hline 3 & .46 & .39 & .34 & .47 & .46 & .36 & .29 & .35 & .48 & .48 & .32 & .66 & - & & & & & & & & & & & & & & \\
\hline 4 & .28 & .27 & .37 & .39 & .39 & .39 & .50 & .30 & .29 & .21 & .65 & .50 & .26 & - & & & & & & & & & & & & & \\
\hline 5 & .35 & .34 & .26 & .39 & .30 & .36 & .36 & .32 & .34 & .36 & .39 & .62 & .62 & .34 & - & & & & & & & & & & & & \\
\hline 6 & .41 & .43 & .36 & .47 & .44 & .36 & .42 & .35 & .43 & .38 & .51 & .65 & .62 & .66 & .55 & - & & & & & & & & & & & \\
\hline 7 & .27 & .26 & .23 & .11 & .16 & .28 & .19 & .11 & .09 & .24 & .18 & .25 & .11 & .10 & .08 & .27 & - & & & & & & & & & & \\
\hline 8 & .38 & .36 & .31 & .41 & .34 & .41 & .31 & .32 & .33 & .30 & .48 & .48 & .26 & .57 & .37 & .50 & .09 & - & & & & & & & & & \\
\hline 9 & .40 & .38 & .33 & .36 & .34 & .31 & .24 & .28 & .40 & .37 & .42 & .42 & .40 & .38 & .40 & .42 & .15 & .55 & - & & & & & & & & \\
\hline \multicolumn{28}{|c|}{ VBS } \\
\hline 1 & .38 & .42 & .27 & .36 & .46 & .31 & .41 & .32 & .34 & .41 & .36 & .46 & .40 & .44 & .38 & .54 & .18 & .51 & .39 & - & & & & & & & \\
\hline 2 & .42 & .26 & .27 & .43 & .39 & .41 & .38 & .40 & .39 & .34 & .32 & .53 & .40 & .45 & .42 & .49 & .10 & .64 & .49 & .70 & - & & & & & & \\
\hline 3 & .47 & .34 & .32 & .51 & .48 & .36 & .47 & .38 & .40 & .43 & .36 & .56 & .49 & .50 & .47 & .63 & .18 & .48 & .37 & .79 & .73 & - & & & & & \\
\hline 4 & .17 & .18 & .34 & .27 & .21 & .15 & .27 & .22 & .17 & .09 & .41 & .26 & .14 & .48 & .21 & .33 & -.11 & .49 & .39 & .56 & .48 & .50 & - & & & & \\
\hline 5 & .19 & .17 & .41 & .26 & .23 & .27 & .26 & .21 & .16 & .12 & .37 & .14 & -.07 & .55 & .003 & .26 & -.13 & .53 & .23 & .58 & .45 & .45 & .64 & - & & & \\
\hline 6 & .53 & .36 & .31 & .46 & .52 & .39 & .46 & .40 & .37 & .35 & .34 & .51 & .44 & .44 & .43 & .60 & .18 & .43 & .32 & .77 & .65 & .84 & .52 & .56 & - & & \\
\hline 7 & .30 & .28 & .19 & .32 & .25 & .09 & .24 & .02 & .18 & .05 & .29 & .17 & .23 & .33 & .20 & .42 & .13 & .24 & .21 & .54 & .34 & .57 & .51 & .59 & .54 & - & \\
\hline 8 & .04 & .21 & .02 & .07 & .04 & .05 & .29 & -.06 & .02 & .009 & .25 & .03 & .005 & .21 & .14 & .20 & .09 & .22 & .14 & .45 & .26 & .37 & .52 & .58 & .38 & .84 & - \\
\hline
\end{tabular}

Note. None of the correlations fell below .30 or above .90. Therefore, there were no issues with factorability or multicollinearity. VPVQ $=$ Violence Propensity

Vignette Questionnaire; PA-AQ = Physical Aggression subscale of the Aggression Questionnaire; VBS = Violent Behaviour Scale. 
Table 5.

Factor Loadings for Exploratory Factor Analysis with Oblique Rotation of the VPVQ, $P A-A Q$ and VBS Items

\begin{tabular}{|c|c|c|c|}
\hline \multirow[b]{2}{*}{ Item } & \multicolumn{3}{|c|}{ Rotated factor loadings } \\
\hline & Factor 1 & Factor 2 & Factor 3 \\
\hline \multicolumn{4}{|l|}{ VPVQ } \\
\hline Vignette 1 & $.77+*$ & -.02 & .05 \\
\hline Vignette 2 & $.67+*$ & -.01 & .04 \\
\hline Vignette 3 & $.76+*$ & -.08 & .01 \\
\hline Vignette 4 & $.66+*$ & .09 & .07 \\
\hline Vignette 5 & $.80+*$ & -.01 & .04 \\
\hline Vignette 6 & $.66+*$ & .08 & -.03 \\
\hline Vignette 7 & $.65+*$ & -.08 & $.19 *$ \\
\hline Vignette 8 & $.53 \dagger *$ & .13 & -.002 \\
\hline Vignette 9 & $.75+*$ & .10 & -.09 \\
\hline Vignette 10 & $.80 \dagger *$ & .03 & -.10 \\
\hline \multicolumn{4}{|l|}{ PA-AQ } \\
\hline 1 & -.08 & $.57 \dagger *$ & $.24^{*}$ \\
\hline 2 & .18 & $.73+*$ & .02 \\
\hline 3 & $.28^{*}$ & $.60+*$ & -.07 \\
\hline 4 & -.01 & $.50+*$ & $.37 *$ \\
\hline 5 & .12 & $.63+*$ & .02 \\
\hline 6 & .17 & $.54 \uparrow *$ & $.25^{*}$ \\
\hline 7 & $.26^{*}$ & .05 & -.03 \\
\hline 8 & .08 & $.38 *$ & $.38 *$ \\
\hline 9 & .18 & $.36^{*}$ & $.18^{*}$ \\
\hline \multicolumn{4}{|l|}{ VBS } \\
\hline 1 & $.23^{*}$ & .01 & $.74 \uparrow *$ \\
\hline 2 & .19 & $.21 *$ & $.56 \dagger^{* *}$ \\
\hline 3 & $.30^{*}$ & .06 & $.72 \dagger^{*} *$ \\
\hline 4 & -.07 & .04 & $.72 \dagger^{*}$ \\
\hline 5 & -.02 & -.14 & $.86^{+*}$ \\
\hline 6 & $.34^{*}$ & -.01 & $.70 \dagger^{*}$ \\
\hline 7 & .11 & $-.39 *$ & $.91 \dagger^{*}$ \\
\hline 8 & -.01 & $-.55 *$ & $1.02 \div *$ \\
\hline
\end{tabular}

Notes. $* p<.05$. ' $\dagger$ ' indicates factor loadings above the established cut-off of .40 . VPVQ $=$ Violence Propensity Vignette Questionnaire; PA-AQ = Physical Aggression subscale of the Aggression Questionnaire; VBS = Violent Behaviour Scale. 
Table 6.

Hierarchical Multiple Regression Examining the Independent Association between the PA-AQ, the VPVQ, and VBS Mean Scores (N = 434)

\begin{tabular}{|c|c|c|c|c|c|c|c|c|c|c|c|c|}
\hline \multirow[t]{2}{*}{ Measure } & \multirow[t]{2}{*}{$R$} & \multirow[t]{2}{*}{$R^{2}$} & \multirow{2}{*}{$\begin{array}{c}\text { Adjusted } \\
R^{2}\end{array}$} & \multirow[t]{2}{*}{$\Delta R^{2}$} & \multirow[t]{2}{*}{$B$} & \multirow[t]{2}{*}{$S E_{B}$} & \multicolumn{2}{|c|}{$95 \% \mathrm{CI}$} & \multirow[t]{2}{*}{$\beta^{\mathrm{a}}$} & \multirow[t]{2}{*}{$p$} & \multirow{2}{*}{$\begin{array}{c}\text { Semi-partial } \\
r\end{array}$} & \multirow{2}{*}{$\begin{array}{c}\text { Semi- } \\
\text { partial } r^{2}\end{array}$} \\
\hline & & & & & & & $\mathrm{LL}$ & UL & & & & \\
\hline Step 1 & .58 & .33 & .33 & $.33 * * *$ & & & & & & & & \\
\hline Constant & & & & & 2.04 & .04 & 1.95 & 2.13 & & .001 & & \\
\hline VPVQ & & & & & 1.62 & .10 & 1.42 & 1.83 & .58 & .001 & .58 & .34 \\
\hline Step 2 & .66 & .44 & .43 & $.10 * * *$ & & & & & & & & \\
\hline Constant & & & & & 1.96 & .04 & 1.88 & 2.05 & & .001 & & \\
\hline VPVQ & & & & & 1.15 & .11 & .93 & 1.37 & .41 & .001 & .36 & .13 \\
\hline VBS & & & & & .23 & .03 & .18 & .28 & .36 & .001 & .32 & .10 \\
\hline
\end{tabular}

Note. VPVQ = Violence Propensity Vignette Questionnaire; VBS = Violent Behaviour Scale; PA-AQ = Physical Aggression Subscale of the Aggression Questionnaire.

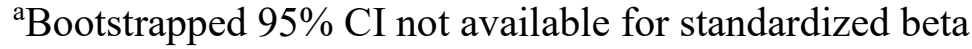

$* * * p<.001$ 
Table 7.

Hierarchical Multiple Regression Examining the Independent Association between the VBS, the VPVQ, and the PA-AQ Mean Scores $(N=434)$

\begin{tabular}{|c|c|c|c|c|c|c|c|c|c|c|c|c|}
\hline \multirow[t]{2}{*}{ Measure } & \multirow[t]{2}{*}{$R$} & \multirow[t]{2}{*}{$R^{2}$} & \multirow{2}{*}{$\begin{array}{c}\text { Adj. } \\
R^{2}\end{array}$} & \multirow[t]{2}{*}{$\Delta R^{2}$} & \multirow[t]{2}{*}{$B$} & \multirow[t]{2}{*}{$S E_{B}$} & \multicolumn{2}{|c|}{$95 \% \mathrm{CI}$} & \multirow[t]{2}{*}{$\beta^{\mathrm{a}}$} & \multirow[t]{2}{*}{$p$} & \multirow{2}{*}{$\begin{array}{l}\text { Semi- } \\
\text { partial } r\end{array}$} & \multirow{2}{*}{$\begin{array}{c}\text { Semi- } \\
\text { partial } \\
r^{2}\end{array}$} \\
\hline & & & & & & & $\mathrm{LL}$ & UL & & & & \\
\hline Step 1 & .45 & .20 & .20 & $.20 * * *$ & & & & & & & & \\
\hline Constant & & & & & .35 & .07 & .21 & .48 & & .001 & & \\
\hline VPVQ & & & & & 2.29 & .26 & 1.74 & 2.80 & .45 & .001 & .45 & .20 \\
\hline Step 2 & .58 & .34 & .32 & $.13^{* * *}$ & & & & & & & & \\
\hline Constant & & & & & -1.23 & .19 & -1.61 & -.88 & & .001 & & \\
\hline VPVQ & & & & & 1.00 & .23 & .53 & 1.44 & .20 & .001 & .16 & .03 \\
\hline PA-AQ & & & & & .77 & .09 & .61 & .96 & .44 & .001 & .36 & .13 \\
\hline
\end{tabular}

Note. VPVQ = Violence Propensity Vignette Questionnaire; VBS = Violent Behaviour Scale; PA-AQ = Physical Aggression

Subscale of the Aggression Questionnaire. Adj. = Adjusted

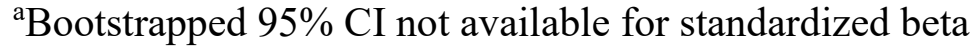

$* * * p<.001$ 
Table 8.

Hierarchical Multiple Regression Examining the Independent Association between the PA-AQ, the VPVQ, and the VBS Factor Scores $(N=434)$

\begin{tabular}{|c|c|c|c|c|c|c|c|c|c|c|c|c|}
\hline \multirow[t]{2}{*}{ Measure } & \multirow[t]{2}{*}{$R$} & \multirow[t]{2}{*}{$R^{2}$} & \multirow[t]{2}{*}{ Adjusted $R^{2}$} & \multirow[t]{2}{*}{$\Delta R^{2}$} & \multirow[t]{2}{*}{$B$} & \multirow[t]{2}{*}{$S E_{B}$} & \multicolumn{2}{|c|}{$95 \% \mathrm{CI}$} & \multirow[t]{2}{*}{$\beta^{\mathrm{a}}$} & \multirow[t]{2}{*}{$p$} & \multirow{2}{*}{$\begin{array}{l}\text { Semi- } \\
\text { partial } r\end{array}$} & \multirow{2}{*}{$\begin{array}{c}\text { Semi- } \\
\text { partial } r^{2}\end{array}$} \\
\hline & & & & & & & LL & UL & & & & \\
\hline Step 1 & .67 & .45 & .45 & $.45 * * *$ & & & & & & & & \\
\hline Constant & & & & & -.02 & .03 & -.08 & .04 & & .44 & & \\
\hline VPVQ & & & & & .69 & .04 & .62 & .76 & .67 & .001 & .67 & .45 \\
\hline Step 2 & .74 & .54 & .54 & $.09 * * *$ & & & & & & & & \\
\hline Constant & & & & & -.04 & .03 & -.09 & .02 & .51 & .16 & & \\
\hline VPVQ & & & & & .52 & .04 & .44 & .59 & .51 & .001 & .45 & .20 \\
\hline VBS & & & & & .35 & .04 & .27 & .42 & .34 & .001 & .30 & .09 \\
\hline
\end{tabular}

Note. VPVQ = Violence Propensity Vignette Questionnaire; VBS = Violent Behaviour Scale; PA-AQ = Physical Aggression Subscale of the Aggression Questionnaire.

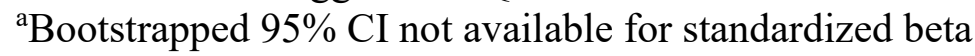
$* * * p<.001$ 
Table 9.

Hierarchical Multiple Regression Examining the Independent Association between the VBS, the VPVQ, and the PA-AQ Factor Scores $(N=434)$

\begin{tabular}{|c|c|c|c|c|c|c|c|c|c|c|c|c|}
\hline \multirow[t]{2}{*}{ Measure } & \multirow[t]{2}{*}{$R$} & \multirow[t]{2}{*}{$R^{2}$} & \multirow[t]{2}{*}{ Adjusted $R^{2}$} & \multirow[t]{2}{*}{$\Delta R^{2}$} & \multirow[t]{2}{*}{$B$} & \multirow[t]{2}{*}{$S E_{B}$} & \multicolumn{2}{|c|}{$95 \% \mathrm{CI}$} & \multirow[t]{2}{*}{$\beta^{\mathrm{a}}$} & \multirow[t]{2}{*}{$p$} & \multirow{2}{*}{$\begin{array}{c}\text { Semi- } \\
\text { partial } r\end{array}$} & \multirow{2}{*}{$\begin{array}{c}\text { Semi- } \\
\text { partial } r^{2}\end{array}$} \\
\hline & & & & & & & LL & $\mathrm{UL}$ & & & & \\
\hline Step 1 & .48 & .23 & .23 & $.23 * * *$ & & & & & & & & \\
\hline Constant & & & & & .05 & .04 & -.02 & .12 & & .18 & & \\
\hline VPVQ & & & & & .48 & .04 & .40 & .56 & .48 & .0001 & .48 & .23 \\
\hline Step 2 & .60 & .36 & .36 & $.13 * * *$ & & & & & & & & \\
\hline Constant & & & & & .06 & .03 & -.01 & .12 & & .07 & & \\
\hline VPVQ & & & & & .16 & .05 & .05 & .26 & .16 & .007 & .12 & .02 \\
\hline PA-AQ & & & & & .47 & .05 & .37 & .57 & .48 & .001 & .36 & .13 \\
\hline
\end{tabular}

Note. VPVQ = Violence Propensity Vignette Questionnaire; VBS = Violent Behaviour Scale; PA-AQ = Physical Aggression Subscale of the Aggression Questionnaire.

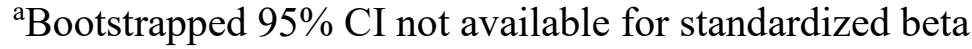

$* * * p<.001$ 


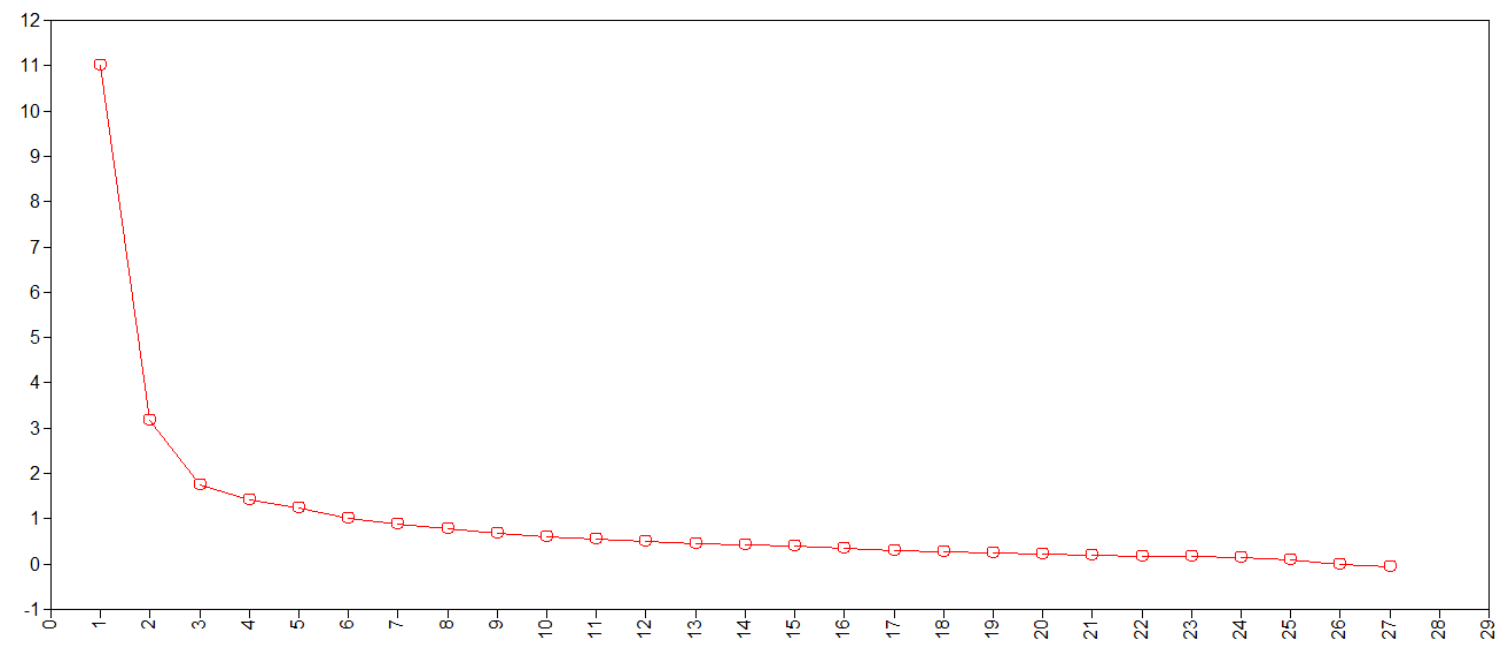

Figure 2. Scree plot for exploratory factor analyses of the distinctiveness of the VPVQ from the PA-AQ and the VBS. The Y axis indicates the eigenvalues for the proposed factors, and the $\mathrm{X}$ axis indicates the number of extracted factors.

\section{Factor Structure of the VPVQ Response Options}

I conducted a third EFA to examine the underlying factor structure of the nine dichotomized response options of the VPVQ using the aforementioned fit criteria, WLSMV estimator from a polychoric correlation matrix, and oblique (Geomin) rotation. The correlations for each of the response options can be found in Table 10. All were in the appropriate range, suggesting no multicollinearity issues and that the matrix was factorable. The range of estimated number of factors to be retained for this EFA was 1-3. Kaiser's criterion, Scree plot (see Figure 3), and MAP suggested 1-factor models, while the Parallel Analysis generally suggested a 3-factor model. The 1-factor model was selected due to the parsimony and goodness of fit to the data with an RMSEA of .048, 95\% CI [.029, .066], a CFI of .983 and a SRMR of .069. The eigenvalue for the retained factor was 5.13, with a proportion of explained variance (for the unrotated model) of .57. The rotated factor loadings of the VPVQ vignettes can be found in Table 11. While the 1- 
factor model was selected, the 2- and 3-factor model information and factor loadings are reported in Appendix D and Tables D1 and D2, given that there was some discordance between the extraction methods. Additionally, given that all the inter-item correlations for the dichotomous variables were unexpectedly positive, I conducted a Spearman's rho correlation analysis to examine the relationships between the VPVQ response options and the mean scores of the PA-AQ and the VBS. The results of this analysis can be found in Table 12.

Table 10.

Polychoric Correlations Between the Dichotomized Response Options $(N=453)$

\begin{tabular}{lccccccccc}
\hline Response Option & 1 & 2 & 3 & 4 & 5 & 6 & 7 & 8 & 9 \\
\hline 1. Report & - & & & & & & & & \\
2. Talk & .60 & - & & & & & & & \\
3. Insult & .57 & .48 & - & & & & & & \\
4. Joke & .61 & .47 & .62 & - & & & & & \\
5. Shove & .55 & .48 & .62 & .60 & - & & & & \\
6. Hit/punch/kick & .54 & .42 & .49 & .40 & .57 & - & & & \\
7. Threaten & .61 & .54 & .59 & .50 & .51 & .40 & - & & \\
8. Ignore & .42 & .35 & .32 & .41 & .51 & .60 & .31 & - & \\
9. Leave & .51 & .56 & .54 & .61 & .60 & .59 & .43 & .58 & - \\
\hline
\end{tabular}

Note. None of the correlations fell below .30 or above .90 . Therefore, there were no issues with factorability or multicollinearity. 
Table 11.

Factor Loadings for Exploratory Factor Analysis with Oblique Rotation of VPVQ Response Options (1-Factor)

\begin{tabular}{lc}
\hline Response Option & $\begin{array}{c}\text { Rotated factor } \\
\text { loading }\end{array}$ \\
\hline Option 1 - Report it to someone & $.77 \dagger$ \\
Option 2 - Talk it out & $.68 \dagger$ \\
Option 3 - Insult him & $.75 \dagger$ \\
Option 4 - Joke about it & $.75 \dagger$ \\
Option 5 - Shove him & $.78 \dagger$ \\
Option 6 - Hit/punch/kick/tackle him & $.71 \dagger$ \\
Option 7 - Threaten to hurt him & $.69 \dagger$ \\
Option 8 - Ignore it & $.62 \dagger$ \\
Option 9 - Leave & $.78 \dagger$ \\
\hline
\end{tabular}

Note. '†' denotes factor loadings greater than .40. Unstandardized factor loadings are provided due to the dichotomous nature of the data, and the use of oblique rotation.

Table 12.

Spearman Correlations Examining the Relationships Between the Dichotomized Response Options and the Mean Scores of the PA-AQ and the VBS $(N=451)$

\begin{tabular}{lcc}
\hline Response Option & PA-AQ Mean Score $[95 \% \mathrm{CI}]$ & VBS Mean Score $[95 \% \mathrm{CI}]$ \\
\hline 1. Report & $-.27^{* *}[-.36,-.18]$ & $-.21^{* *}[-.30,-.12]$ \\
2. Talk & $.03[-.10, .15]$ & $-.02[-.14, .10]$ \\
3. Insult & $.31^{* *}[.21, .39]$ & $.23^{* *}[.12, .32]$ \\
4. Joke & $.04[-.06, .13]$ & $.07[-.03, .16]$ \\
5. Shove & $.26^{* *}[.17, .34]$ & $.13^{* *}[.03, .22]$ \\
6. Hit/punch/kick & $.48^{* *}[.41, .56]$ & $.41^{* *}[.32, .49]$ \\
7. Threaten & $.41^{* *}[.33, .49]$ & $.38^{* *}[.30, .46]$ \\
8. Ignore & $-.09[-.19, .003]$ & $-.07[-.17, .03]$ \\
9. Leave & $-.24 * *[-.33,-.15]$ & $-.26^{* *}[-.35,-.15]$ \\
\hline
\end{tabular}

Note. $\mathrm{PA}-\mathrm{AQ}=$ Physical Aggression subscale of the Aggression Questionnaire; VBS = Violent Behaviour Scale; $* p<.05 * * p<.01 * * * p<.001$ 


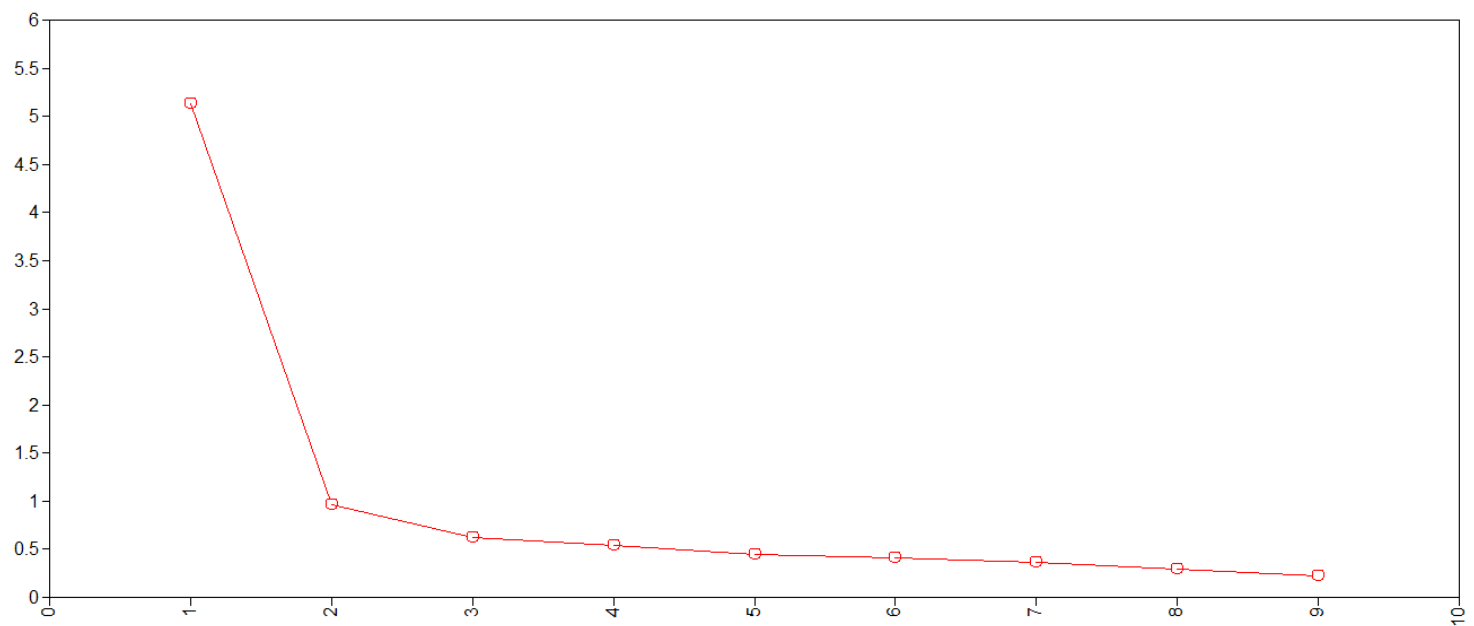

Figure 3. Scree plot for exploratory factor analyses of the dichotomized VPVQ response options. The $\mathrm{Y}$ axis indicates the eigenvalues for the proposed factors, and the $\mathrm{X}$ axis indicates the number of extracted factors.

Though I attempted to conduct an EFA on the nine continuous response option variables, I was unable to obtain successful convergence for any of the models, except for the 1-factor model, and thus I was unable to conduct a Parallel or MAP analysis of these results. Additionally, the interitem correlations (see Table 13), while demonstrating no issues with multicollinearity, were below the cut-off of .30, indicating problems with the factorability of this data. Despite this, and due to the purely exploratory nature of this analysis, a few preliminary results were extracted. Kaiser's rule suggested a 4-factor structure, with the eigenvalues for the extracted factors as follows: $\mathrm{EV}_{1}=2.33, \mathrm{EV}_{2}=1.37, \mathrm{EV}_{3}=1.18$, and $\mathrm{EV}_{4}$ $=1.04$. The number of proposed factors extracted from the scree plot (see Figure 4) were unclear, but this method seemed to suggest a 1-factor structure. While I was unable to adequately examine the other models due to lack of convergence, 
the fit statistics for the 1-factor model did not indicate good fit, with RMSEA $=.315$, $95 \%$ CI $[.300, .329], \mathrm{CFI}=.193$, and $\mathrm{SRMR}=.123$.

\section{Table 13.}

Pearson Correlations Between the Continuous Response Options $(N=471)$

\begin{tabular}{lccccccccc}
\hline Response Option & 1 & 2 & 3 & 4 & 5 & 6 & 7 & 8 & 9 \\
\hline 1. Report & - & & & & & & & & \\
2. Talk & -.14 & - & & & & & & & \\
3. Insult & -.13 & -.20 & - & & & & & & \\
4. Joke & -.20 & -.28 & -.16 & - & & & & & \\
5. Shove & -.06 & -.16 & -.18 & .04 & - & & & & \\
6. Hit/punch/kick & -.18 & -.27 & -.23 & .26 & .05 & - & & & \\
7. Threaten & -.24 & -.32 & -.35 & .05 & -.04 & .23 & - & & \\
8. Ignore & -.21 & -.26 & -.24 & .27 & .06 & .20 & .29 & - & \\
9. Leave & .22 & .04 & -.22 & -.31 & -.10 & -.21 & .25 & -.29 & - \\
\hline
\end{tabular}

Note. None of the correlations fell above .90, indicating no issues with multicollinearity. However, almost all the variables were below the factorability threshold of .30, indicating problems with the factorability of this data. 


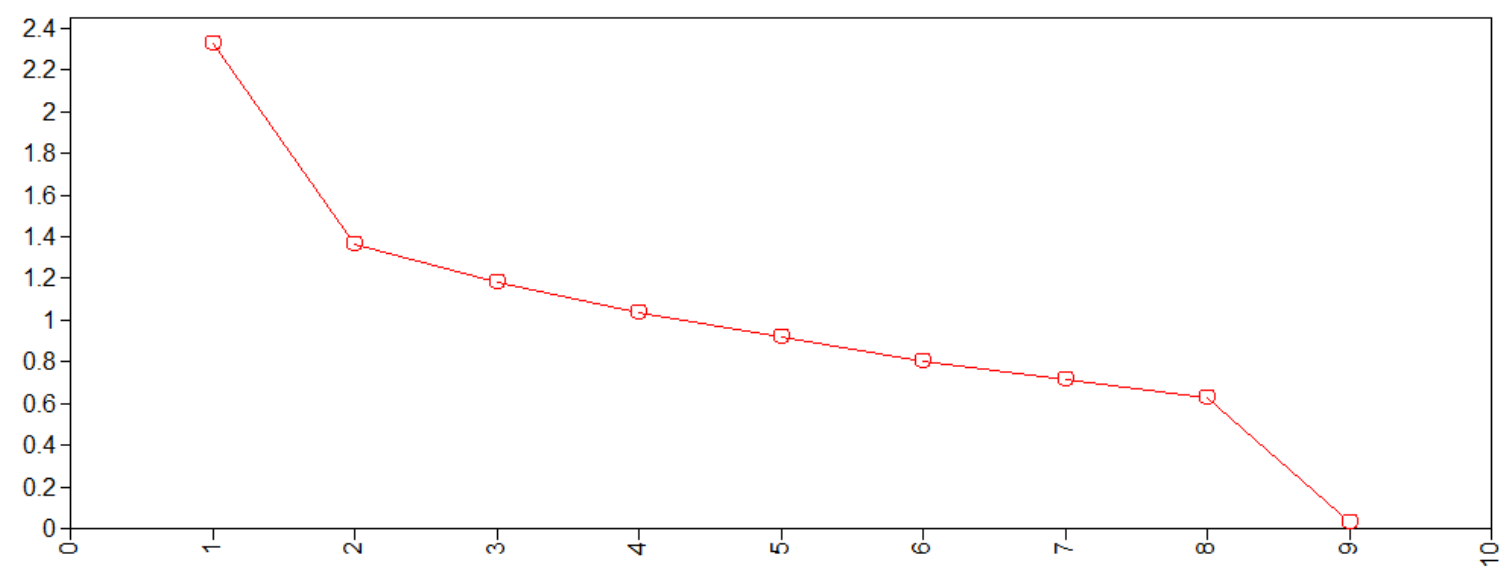

Figure 4. Scree plot for exploratory factor analyses of the continuous VPVQ response options. The $\mathrm{Y}$ axis indicates the eigenvalues for the proposed factors, and the $\mathrm{X}$ axis indicates the number of extracted factors.

\section{Discussion}

I conducted two EFAs and a regression analysis to examine the factor structure and distinctiveness of the VPVQ. I also conducted a secondary, purely exploratory EFA to examine the factor structure of the VPVQ response options. The VPVQ vignettes were best represented by a 1-factor structure, suggesting that they are represented by a single underlying construct. The VPVQ vignette items also factored separately from the PA-AQ and VBS items in the distinctiveness EFA, and the supplementary semi-partial correlations further demonstrated that the VPVQ mean and factor scores had a small unique association with responding on the PA-AQ and the VBS after controlling for the effect of the other measure. The secondary EFA for the response options was unsuccessful at converging on an interpretable model. Discussion regarding the results of the three tests follow. 


\section{VPVQ Factor Structure \& Distinctiveness}

Taken together, the results of the first two EFAs suggest that the VPVQ is assessing a unique underlying construct that is distinct from the other measures, and that the unique relationship is small to moderately strong. Though the limits of the exploratory factor analytic methods do not allow me to specify what the content of this unique construct is, the results of the EFA do indicate that the domain is represented by a single, unidimensional model.

Though I did not propose any specific hypotheses, Nunes and colleagues’ (2019) suggestion that the VPVQ might be measuring reactive violence seems to be plausible. The exclusion of the vignettes depicting proactive violence in the development stage, as well as the instigations depicted in the remaining vignettes seem to support this suggestion. Replicating this study using a measure of reactive aggression such as the Impulsive/Premeditated Aggression Scale (IPAS; Stanford et al., 2003) or the ReactiveProactive Aggression Questionnaire (RPQ; Raine et al., 2006) may be a prudent next-step to examine the degree of overlap with this construct. Examining the uniqueness and overlap of the reactive violence construct, as well as the degree of association with proactive violence would help to clarify what unique information the VPVQ vignettes are assessing.

Notably, while there was no cross-loading of the PA-AQ and VBS items in the VPVQ factor based on my established criteria, a few items from these measures did have somewhat elevated sub-threshold factor loadings on the VPVQ factor. Specifically, the items that address physical acts of violence (e.g., "if somebody hits me, I hit them back" and the reverse-scored "I can think of no good reason for ever hitting another person" 
from the PA-AQ and "how many times have you hit a person with the intention of hurting them" and "how many times have you injured someone on purpose [e.g., left bruises, caused visible bleeding or broken bones, etc.]" from the VBS) had elevated loadings on this factor. This seems to further support the supposition that the construct the VPVQ is assessing is reactive violence as compared to aggression, as distinguished by Bushman and Anderson (2001).

Anderson, Hildreth, and Howland's (2015) work on responsivity to status threat may also provide a relevant perspective, as the 1-factor structure of the VPVQ might suggest that violent responding may be irrespective of the degree or context of the slight. Dagirmanjian and colleagues (2017) found similar results using qualitative interview data from tradesmen. In their study, the most common justifications men provided for male violence reflect public incidents of perceived humiliation or threats to the elements that make them look the strongest, wealthiest, or most attractive to female partners (i.e., participants' definition of “being a man"). The VPVQ vignettes all contain slightly different scenarios, but a common threat to status exists in each vignette. Some contain threats to manhood, while others contain threats to property. The results of that study, and the 1 -factor structure demonstrated in our study seem to suggest that the nature of the slight is not important, but rather that the violent response may be elicited in response to threat more generally. Using confirmatory factor analytic or Item Response Theory (Clark \& Watson, 2019) methods to re-examine the factor structure and confirm what underlying construct(s) form the basis of the VPVQ vignettes considering these results would be an important next step. Once the nature of the 
underlying construct of the VPVQ is established, it would also be important to more closely and rigorously examine the predictive validity of that construct.

It would also be prudent to examine the impact that anger would have on responding to the VPVQ vignettes. Research demonstrates that anger is an important factor to consider when measuring aggressive or violent behaviour (White \& Turner, 2014). A meta-analysis also demonstrated that self-reported anger was a predictive factor for violent behaviour (Chereji, Pintea, \& David, 2012). Given this, it would be beneficial to examine whether, and to what extent, responding on the VPVQ is impacted by anger. This is particularly relevant given White and Turner's (2014) results demonstrating that anger was most strongly related to reactive aggression, and the supposition that the VPVQ is measuring reactive but not proactive violence. Future research using the Anger scale of the AQ to replicate the current study may provide insight as to the extent to which the effect of generalized anger is accounted for by the VPVQ. Examining the independence of these two constructs would also serve to demonstrate whether the VPVQ may be a useful predictive measure.

It would also be useful to extend the results of the current study to offender samples, and other community samples outside of the original validation study (Clark \& Watson, 2019), given Nunes and colleagues' (2019) intent to create a measure that is effective for both settings. I was unable to examine the factor structure of the VPVQ vignettes on the original offender data for this study due to insufficient sample size. While I would hypothesize that the current factor structure would replicate in offender samples, exploration of this question with an offender sample size sufficient for factor analytic methods would be beneficial. Similarly, I would expect this factor structure to 
replicate in other samples of community men, though it is still important to test this assumption in both an exploratory and confirmatory way.

Also, given that the VPVQ vignettes are coded for responding across both vignettes (i.e., vignette is coded as 1 if a violent response is selected at the initial provocation or the response phase), it would be important in future research to reexamine the factor structure and violent response rate over each of the two vignette choices separately. It is possible that each round of responding on the VPVQ may be assessing something unique unto themselves. For example, the first round of responding may be assessing response to a provocation, whereas the second round may be assessing a response to escalation. It would be important to examine to what extent, if any, this impacts the VPVQ.

An important limitation that I need to address is the use of the VBS in this study. While the original Nunes and colleagues (2019) study demonstrated support for its use, a couple of problematic results arose in the current study. First, I treated the VBS as a categorical variable with 10 categories in the EFA. This meant that the sample size of some of the categories was small, which may have contributed to the small correlations for some of the items and thus a restricted factor structure. Second, the last item of the VBS had a factor loading greater than 1 (i.e., a Heywood case), which suggests a problem with this factor. It would be beneficial to replicate this analysis while treating the VBS as a continuous variable to see if the problematic results persist. It may be appropriate to treat the VBS as a continuous variable despite the last " 9 times or more" category given the number and range of categories (Clark \& Watson, 2019), which should 
counteract the small sample size issue. While the results of the EFAs and the regression analyses including and excluding the problematic VBS items were consistent, should these problems persist when treating the VBS as continuous, then replication of this study with a more reliable measure of violent behaviour will also be necessary.

Additionally, it is important to acknowledge the limitations afforded by the regression analysis. While the semi-partial correlations and the $R^{2}$ change for each step of the hierarchical regression were examined to supplement the distinctiveness EFA, this method does not allow us to make absolute conclusions about the results. While it lends good preliminary evidence to the conclusion that the VPVQ is measuring a unique construct, other conclusions, such as the interference of other elements of the measures unrelated to the construct (e.g., the response modes discussed earlier) cannot be ruled out using this method. It would be important for future research to improve on this method, for example by replicating this study with non-self report outcomes, such as official records of conviction or police contact, or behavioural observation. More closely examining the squared semi-partial correlations to test the incremental contribution of each measure using a more rigorous methodology would provide a stronger conclusion than that provided by these preliminary results. Examining the convergent and divergent validity of the VPVQ with measures of other constructs that the PA-AQ and VBS are convergent and divergent with, such as impulsivity, might also be beneficial.

While the 1-factor structure was the most parsimonious, the 2-factor model was examined in relation to the evolutionary psychology literature on male sexual protection and possession threat. The rotated loadings indicated a tendency for the vignettes depicting instigation against a female to factor distinctly from the other vignettes. This is 
partially in line with my examination of the evolutionary psychological literature, which suggested that those threats against an intimate partner or relationship would factor separately. While this was generally the case, one other vignette, the guest harassing the female host, also factored into the second factor. This may suggest that a more general male-as-protector role may be present in the vignette structure. The cross-loading of the interloper vignette and the loading of the 'disrespecting your girlfriend/wife' vignette in factor 1 rather than factor 2 (contrary to what the results of Chen [2015] would suggest) might further suggest a general status threat versus protector structure. While my current binary coding of the VPVQ responses demonstrated the 1-factor structure, and despite the statistical adjustments that were made to account for the limitations associated with the use of binary data, the limited variability in this format may have unduly restricted the factor structure. This may have resulted in this factor structure being unfairly rejected. It would be important to examine whether the 1-factor structure of the VPVQ would still emerge if the vignettes were coded ordinally.

Once these issues are addressed, it is important to consider how the VPVQ might be useful in application. If subsequent replications and examination of the validity of the VPVQ demonstrate its effectiveness in multiple settings, this will increase the opportunity for cohesion and convergence for research in lab and applied forensic settings, as intended by Nunes and colleagues (2019). If the 1factor structure is replicated and confirmed, the underlying construct is established to be violence, and the VPVQ's predictive validity for said construct is established, this might suggest that the VPVQ vignettes can be used to predict 
violent behaviour. This might also suggest that practitioners could equally use any or all the vignette situations to guide clinical treatment, without sacrificing validity or variable context, allowing clients to explore the violent intentions and reactions in a safe environment.

Additionally, while there is evidence to suggest that using self-report measures alone may not be effective at predicting violent behaviour (Campbell, French, and Gendreau, 2007), rarely does this happen in practice. Self-report measures such as those discussed here are seldom used in isolation for evaluation. More often in forensic and other settings, self-report measures are supplemented by other measures with complementary outcomes, such as behavioural observations or collateral reporting. Information gathered from multiple sources and using multiple methods has been demonstrated to be more effective when used in conjunction than in isolation (Kasper, Chan, \& Freedman, 2017; Neal \& Grisso, 2014). The semi-partial correlations suggest that the VPVQ vignettes, the PA-AQ, and the VBS, when considered together in a battery, might all contribute important information to assessment of violent behaviour.

Finally, if the underlying construct is confirmed to be violence, it would be important to examine the extent to which the VPVQ converges with other indicators of violent behaviour to address the question of how well the VPVQ assesses this construct. For example, conducting a longitudinal study to compare the rates of violent responding on the VPVQ to rates of observed violent behaviour or recidivism would be crucial.

\section{Factor Structure of the VPVQ Response Options}

I also attempted to examine the factor structure of the VPVQ response options. I had planned to conduct this analysis in a variety of ways, treating the response options as 
both dichotomous and continuous. This process was purely exploratory, and thus I did not propose any specific hypotheses. I was unable to conduct an EFA on either of the continuous variables. The first set of count variables contained too many empty cells to conduct the analysis adequately, and the interitem correlations for the second set of count variables did not reach the threshold for factorability. Perhaps due to this fact, the purely exploratory attempt to conduct an EFA on the continuous variables yielded nonconvergence for all but the 1 -factor model. The results of the dichotomized variable EFA indicate that the response options presented with a 1 -factor structure, with all the items loading onto one common factor. This would suggest that the response options, contrary to the individualized content, are represented by a single underlying construct.

However, it is important to acknowledge that this result was problematic, both statistically and theoretically. Theoretically, the content of the VPVQ response options does not align with a 1 -factor structure. While all nine of the categories are nominal descriptors of actions participants can take, some are physical and violent in nature, while others are passive or verbal. From the perspective of the content, a 1-factor structure for these items seems contradictory, in that those items that describe physical aggression or violence, such as the option 'hit/punch/kick/tackle him' or the option 'threaten him', should not factor together with more passively aggressive items such as the option 'joke about it', nor with the disengagement items such as 'ignore it.'

This issue also seemed to be reflected in the interitem polychoric correlations. While it would follow that those items that are more physical in nature should be negatively associated with the more verbal or non-confrontational items, this was not the case in my study. Rather, all the interitem correlations were positive, suggesting that 
selecting one of the nine response options is simply associated with selecting another item regardless of its position on the violence spectrum. This may be indicating that some response variability was lost in this coding method, particularly given that there was an almost equal frequency of participants who selected each response, and those who did not. Moreover, the results of the Spearman correlations between the VPVQ response option items and the PA-AQ and VBS mean scores showed the expected relationships, with the violent responses options being positive correlated with the PA-AQ and the VBS. The non-violent items, with the exception of "insult him", were negatively (and often weakly) correlated. These results further suggest a loss of variability in examining the response option items themselves as compared to when they are considered in tandem with other, convergent information.

In a similar vein, while the interitem correlations for the continuous data were somewhat more theoretically aligned, some of the correlations were still problematic. These variables also had low interitem correlations that did not meet the threshold for factorability, suggesting that their relationships, regardless of the content, may not be that strong. These results, considered as a whole, may suggest that a non-trivial amount of variability in responding was lost when I created these variables, but that the response options themselves may still be appropriate.

It is important to recognize that non-independence may also have contributed to this issue. While the steps that I took to code these items were intended to minimize the issue of independence (i.e., dichotomizing a general "did they ever select response option $\mathrm{x}$ for any of the vignettes"), it is possible that this attempt was unsuccessful. Recall that the raw VPVQ answers are given twice for each vignette, and the second scenario for 
each vignette that participants receive varies depending on their first selection. For this reason, it is possible that, despite collapsing the responses to "have they ever"-style coding, that the correlations might reflect a more general selection pattern. However, the fact that none of the correlations displayed a perfect linear relationship should contradict this supposition.

Regardless, these correlations are problematic. Any future EFA research to examine the factor structure of the response options should devise a way to more accurately account for the interdependence of the vignette response pattern. Alternatively, Goldberg and Velicer (2006) and Watson (2017) have indicated that that EFA should not be conducted on nominal or 'checklist' data, and that EFA is most appropriate for scale data. Perhaps it is simply that the response options were not an appropriate data format for this test.

If this is not the case, and a variable can be derived that allows for examination of the factor structure of the response options, then future EFA research on this topic would benefit from examining to what extent the number and order of the response options may contribute to the results, or improve the psychometric properties of the VPVQ. Nunes and colleagues (2019) indicated that they provided the number and content of the response options in this way to maximize the approximation to real-world behaviours. However, research has demonstrated that a more limited number of response options and a specific option placement order (Cabooter, Weijters, Geuens, \& Vermeir, 2016; Lozano, GarciaCueto, \& Muniz, 2008; Simms, Zelazny, Williams, \& Bernstein, 2019) may improve the reliability and validity of a scale (Finn, Ben-Porath, \& Tellegen, 2015). While the reliability for the original community sample VPVQ study was high, seemingly 
contradicting this suggestion, those statistics represent the reliability for the overall VPVQ measure and may not apply to the response options more specifically. Also, as I combined the endorsement frequencies for both vignettes (i.e., "did they ever, over either vignette option, select option X"), future research would benefit from teasing out whether there is a difference in the response rates, use of the response options, or factor structure of the options over each of the two response choices separately, similar to the earlier suggestion for the VPVQ vignettes.

The fit statistics for the factor models that were extracted from the dichotomous data, as well as the 1-factor model that was able to successfully converge for the continuous data, also indicated some problems with model fit. Specifically, while three of the four factor extraction methods suggested a 1-factor structure for the dichotomous data with reasonable fit, the confidence intervals for the RMSEA for this model contained the cut-off value of .06, indicating poor fit. Additionally, when I more closely examined the fit statistics of the 3-factor structure for the dichotomized data proposed by the Parallel Analysis, the RMSEA confidence intervals no longer contained the cut-off value, but they were extremely wide. Concerning the fit statistics of the 1-factor structure of the continuous data, this model produced fit statistics that greatly and unanimously surpassed their threshold for good fit, further demonstrating the problematic use of EFA procedures on this data.

Monroe and Cai (2015) conducted a Monte Carlo simulation study to examine the effectiveness of RMSEA and its confidence intervals for different population RMSEA values, sample size, and number of variable categories. They demonstrated that the RMSEA is dependent on the number of variable categories. When the sample size was 
500 (i.e., a similar range to the current study), and the variables had 2 categories, the RMSEA estimate was always around .01-.03, the CIs were always wide, and they never contained the population estimate. The sample RMSEA remained in this range, even when the population RMSEA was increased to a traditionally non-significant value based on continuous cut-offs, suggesting a tendency to misidentify the model in these situations. These results matched with the ones I found from my model, further suggesting this model was problematic.

However, Maydeu-Olivares, Shi, and Rosseel (2018) found contrasting results in another simulation study with similar parameters and small models (i.e., 10 variables, like the current study) with moderate skewness and kurtosis. Here, RMSEA and its confidence intervals performed well, though not as well as SRMR for small models with moderate skewness and kurtosis. In the current study, both the RMSEA and SRMR performed more poorly than in Maydeu-Olivares, Shi, and Rosseel's simulation. Such contrasting results, in both the established literature and the current study, further underscores the need to re-evaluate the methods and appropriateness of examining the factor structure of the response options of the VPVQ.

It is important to acknowledge that this does not, necessarily, negate the results I observed in the EFA examining the factor structure of the VPVQ vignettes. Consider again Goldberg and Velicer's (2006) suggestion to not factor analyze non-scale data. This criticism does not necessarily apply to the VPVQ vignettes themselves, as the response options can be considered the 'scale' for the VPVQ vignettes. The response options themselves, on the other hand, do not necessarily have an equivalent unique scale. It is also important to again point out that Nunes and colleagues (2019) provided this nominal 
scale with these options in order to provide as accurate and variable a list of potential real-world behaviours as possible, so as not to limit possible responding. Therefore, their individual content and not necessarily their underlying factor structure may be more important to consider.

Finally, the factor loadings for the dichotomized data were theoretically problematic as well. As with the correlations, none of the factor loadings that met the designated loading threshold loaded negatively on the factors with theoretically different items. This would not necessarily follow if these items were unique. Similarly, when I looked at the patterns of the factor loadings for the 3-factor structure, the items that loaded together did not follow any logical pattern. While it may be that these options truly do load together in a single factor, it seems more likely that the model for the response options is incorrect, or that the response option data is not appropriate to be factor analyzed. This proposition seems particularly likely when you consider the factor loadings in conjunction with the previous discussion.

To conclude, EFA and hierarchical regression procedures suggest that the VPVQ vignettes are represented by a 1-factor structure, and that the VPVQ has a small-tomoderate but unique association with the other measures used for the current study. More research is necessary to further examine, confirm, and improve the psychometric properties of the VPVQ. If further research converges on the conclusions of the current study, that would expound on the exact construct reflected in the VPVQ vignettes and would clarify its usefulness in research and clinical settings. Future research should serve to improve the psychometric properties of the VPVQ and confirm the factor structure and use of the tool in a new sample of community males and offenders. 
Conversely, no factor structure was established for the VPVQ response options. A lack of convergence and problematic correlations, fit statistics, and factor loadings demonstrated that the models for the response options were not adequate. The results of these exploratory results suggest that the response options data may not be appropriate for factor analytic methods. Importantly, this may not be a strong concern, given Nunes and colleagues' (2019) assertion that the nominal categories were meant to more closely reflect real-world behaviour. 


\section{References}

Allen, M. (2018). Police-reported crime statistics in Canada, 2017. Juristat. Report No. 85-002-X. Retrieved from Statistics Canada: https://www150.statcan.gc.ca/n1/pub/85-002-x/2018001/article/54974-eng.htm

Anderson, C. A, Hildreth, J. A. D., \& Howland, L. (2015). Is the desire for status a fundamental human motive? A review of the empirical literature. Psychological Bulletin, 141(3), 574-601. doi: 10.1037/a0038781

Anderson, C. A., \& Bushman, B. J. (1997). External validity of "trivial” experiments: The case of laboratory aggression. Review of General Psychology, 1, 19-41.

Anderson, C. A., \& Bushman, B. J. (2002). Human aggression. Annual Review of Psychology, 53, 27-51.

Anderson, C. A., Lindsay, J. J., \& Bushman, B. J. (1999). Research in the psychological laboratory: Truth or triviality? Current Directions in Psychological Science, 8, 39. doi: $10.1111 / 1467-8721.00002$

Ansara, D. L., \& Hindin, M. J. (2011). Psychosocial consequences of intimate partner violence for women and men in Canada. Journal of Interpersonal Violence, 26(8), 1628-1645. doi: $10.177 / 0886260510370600$

Aydin, A., \& Akgun, S. (2014). Summary: The relationships between anger, narcissism, and reactive and proactive aggression in adolescence. Turkish Journal of Psychology, 29(73), 57-59.

Bendalos, D. L., \& Finney, S. J. (2010). Factor analysis: Exploratory and confirmatory. In G. R. Hancock \& R. O. Mueller. (Ed.). The Reviewer's Guide to Quantitative 
Methods in the Social Sciences (p. 110-132). New York, NY, USA: Routledge University Press.

Bryant, F. B., \& Smith, B. D. (2001). Refining the architecture of aggression: A measurement model for the Buss-Perry Aggression Questionnaire. Journal of Research in Personality, 35, 138-167. doi: 10.1006/jrpe.2000.2302

Bushman, B. J., \& Anderson, C. A. (2001). Is it time to pull the plug on the hostile versus instrumental aggression dichotomy? Psychological Review, 108(1), 273-279. doi: 10.1037//0033-295X.108.1.273

Buss, A. H., \& Durkee, A. (1957). An inventory for assessing different kinds of hostility. Journal of Consulting Psychology, 21(4), 343-349. doi: 10.1037/h0046900

Buss, A. H., \& Perry, M. (1992). The Aggression Questionnaire. Journal of Personality and Social Psychology, 63(3), 452-459.

Buss, A. H., Durkee, A., \& Baer, M. B. (1956). The measurement of hostility in clinical situations. The Journal of Abnormal and Social Psychology, 52(1), 84-86.

Cabooter, E., Weijters, B., Geuens, M., \& Vermeir, I. (2016). Scale format effects on response option interpretation and use. Journal of Business Research, 69, 25742584. doi: 10.1016/j.jbusres.2015.10.138

Campbell, M. A., French, S., \& Gendreau, P. (2007). Assessing the utility of risk assessment tools and personality measures in the prediction of violent recidivism for adult offenders. Report prepared for the Department of Public Safety. Available online: https://www.publicsafety.gc.ca/cnt/rsrcs/pblctns/rsk-ssmnttls/rsk-ssmnt-tls-eng.pdf 
Caron, P.-O. (2018). Minimum average partial correlation and parallel analysis: The influence of oblique structures. Communications in Statistics - Simulation and Computation, [Online First]. doi: 10.1080/03610918.2018.1433843

Chereji, S. V., Pintea, S., \& David, D. (2012). The relationship of anger and cognitive distortions with violence in violent offender's population: A meta-analytic approach. The European Journal of Psychology Applied to Legal Context, 4(1), 59-77.

Chen, G. M. (2015). Losing face on social media: Threats to positive face lead to an indirect effect on retaliatory aggression through negative affect. Communication Research, 42(6), 819-838. doi: 10.1177/0093650213510937

Clark, L. A., \& Watson, D. (1995). Constructing validity: Basic issues in objective scale development. Psychological Assessment, 7(3), 309-319.

Clark, L. A., \& Watson, D. (2019). Constructing validity: New developments in creating objective measuring instruments. Psychological Assessment, [Online First]. doi: $10.1037 /$ pas0000626

Costello, A. B., \& Osborne, J. W. (2005). Best practices in exploratory factor analysis: Four recommendations for getting the most from your analysis. Practical Assessment, Research, \& Evaluation, 10(7). Available online: http://pareonline.net/getvn.asp?v=10\&n=7

Dagirmanjian, F. B., Mahalik, J. R., Boland, J., Colbow, A., Dunn, J., Pomarico, A., \& Rappaport, D. (2017). How do men construct and explain men’s violence? Journal of Interpersonal Violence, 37(15), 2275-2297. doi: $10.1177 / 0886260515625511$ 
DeVellis, R. F. (2017). Factor analysis. In Scale Development: Theory and Applications (p. 148-199). Los Angeles, CA: Sage Publications

Ennis, L., Toop, C., Jung, S., \& Bois, S. (2017). Instrumental and reactive intimate partner violence: Offender characteristics, reoffence rates, and risk management. Journal of Threat Assessment and Management, 4(2), 61-76. doi: $10.1037 / \operatorname{tam} 0000080$

Euler, F., Stienlin, C., \& Stadler, C. (2017). Distinct profiles of reactive and proactive aggression in adolescents: associations with cognitive and affective empathy. Child and Adolescent Psychiatric Mental Health, 11(1). Online First. doi: $10.1186 / \mathrm{s} 1303-016-0141-4$

Finn, J. A., Ben-Porath, Y. S., \& Tellegen, A. (2015). Dichotomous versus polychotomous response options in psychopathology assessment: Method of meaningful variance? Psychological Assessment, 27(1), 184-193. doi: $10.1037 /$ pas0000044

Farrell, C., \& Zimmerman, G. M. (2018). Is exposure to violence a persistent risk factor for offending across the life course? Examining the contemporaneous, acute, enduring, and long-term consequences of exposure to violence on property crime, violent offending, and substance use. Journal of Research in Crime and Delinquency, 55(6), 728-765. doi: 10.1177/0022427818785207

Fite, P. J., Raine, A., Stouthamer-Loeber, M., Loeber, R., \& Pardini, D. A. (2010). Reactive and proactive aggression in adolescent males: Examining differential outcomes 10 years later in early adulthood. Criminal Justice and Behaviour, 37(2), 141-157. doi: 10.1177/0093854809353051 
Flora, D. B., LaBrish, C., \& Chalmers, R. P. (2012). Old and new ideas for data screening and assumption testing for exploratory and confirmatory factor analysis. Frontiers in Psychology, 3(55), 1-22. doi: 10.3389/psyg.2012.00055

Garrido, L. E., Abad, F. J., \& Ponsoda, V. (2011). Performance of Velicer's Minimum Average Partial factor retention method with categorical variables. Educational and Psychological Measurement, 71(3), 551-570. doi:

$10.1177 / 0013164410389489$

Gerevich, J., Bacskai, E., \& Czobor, P. (2007). The generalizability of the Buss-Perry Aggression Questionnaire. International Journal of Methods in Psychiatric Research, 16(3), 124-136. doi: 10.1002/mpr.221

Goldberg, L. R., \& Velicer, W. F. (2006). Principles of exploratory factor analysis. In S. Stack (Ed.). Differentiating normal and abnormal personality: Second edition, (p. 209-237). New York, NY: Springer.

Grych, J., \& Hamby, S. (2014). Advancing the measurement of violence: Challenges and opportunities. Psychology of Violence, 4(4), 363-368. doi: 10.1037/a0037886

Hilton, N. Z., Harris, G. T., \& Rice, M. E. (2003). Correspondence between self-report measures of interpersonal aggression. Journal of Interpersonal Violence, 18(3), 223-239. doi: 10.1177/0886260502250065

Hoddenbagh, J., Zhang, T., \& McDonald, S. (2014). An estimation of the economic burden of violent victimization in Canada, 2009. Report No. J4-34/2014-PDF. Retrieved from Department of Justice Government of Canada: https://justice.gc.ca/eng/rp-pr/cj-jp/victim/rr14_01/rr14_01.pdf 
Holgado-Tello, F. P., Chacon-Moscoso, S., Barbero-Garcia, I., \& Vila-Abad, E. (2010). Polychoric versus Pearson correlations in exploratory and confirmatory factor analysis of ordinal variables. Quality \& Quantity, 44, 153-166. doi: $10.1007 / \mathrm{s} 11135-008-9190-\mathrm{y}$

Jones, S., \& Miller, J. D. (2012). Psychopathic traits and externalizing behaviours: A comparison of self- and informant reports in the statistical prediction of externalizing behaviors. Psychological Assessment, 24(1), 255-260. doi: $10.1037 / \mathrm{a} 0025264$

Kasper, J. D., Chan, K. S., \& Freedman, V. A. (2017). Measuring physical capacity: An assessment of a composite measure using self-report and performance-based items. Journal of Aging and Health, 39(2), 289-309. doi:

$10.1177 / 0898264316635566$

Kroner, D. G., Mills, J. F., \& Morgan, R. D. (2006). Socially desirable responding and the measurement of violent and criminal risk: self-report validity. Journal of Forensic Psychology Practice, 6(4), 27-42. doi: 10.1300/158v06n04_02

Ledesma, R. D., \& Valero-Mora, P. (2007). Determining the number of factors to retain in EFA: An easy-to-use computer program for carrying out parallel analysis. Practical Assessment, Research, \& Evaluation, 12(2). Retrieved from: http://pareonline.net/getvn.asp? $\mathrm{v}=12 \& \mathrm{n}=2$

Loza, W., \& Green, K. (2003). The Self-Appraisal Questionnaire: A self-report measure for predicting recidivism versus clinician-administered measures: A 5-year follow-up study. Journal of Interpersonal Violence, 18(7), 781-797. doi: $10.1177 / 0886260503253240$ 
Lozano, L. M., Garcia-Cueto, E., \& Muniz, J. (2008). Effect of number of response categories on the reliability and validity of rating scales. Methodology, 4(2), 7379. doi: $10.1027 / 1614-2241.4 .2 .73$

Mathie, N. L., \& Wakeling, H. C. (2011). Assessing socially desirable responding and its impact on self-report measures among sexual offenders. Psychology, Crime, \& Law, 17(3), 215-237. doi: 10.1080/10683160903113681

Maydeu-Olivares, A., Shi, D., \& Rosseel, Y. (2018). Assessing fit in structural equation models: A Monte Carlo evaluation of RMSEA versus SRMR confidence intervals and tests of close fit. Structural Equation Modelling: A Multidisciplinary Journal, 25(3), 389-402. doi: 10.1080/10705511.2017.1389611

McKay, M. T., Perry, J. L., \& Harvey, S. A. (2016). The factorial validity and reliability of three versions of the Aggression Questionnaire using confirmatory factor analysis and exploratory structural equation modelling. Personality and Individual Differences, 90, 12-15. doi: 10.1016/j.paid.2015.10.028

McNeish, D. (2016). Exploratory factor analysis with small samples and missing data. Journal of Personality Assessment, 99(6), 637-652. doi:

$10.1080 / 00223891.2016 .1252382$

Mills, J. F., \& Kroner, D. G. (2006). Impression management and self-report among violent offenders. Journal of Interpersonal Violence, 21(2), 178-192. doi: $10.1177 / 0886260505282288$

Monroe, S., \& Cai, L. (2015). Evaluating structural equation models for categorical outcomes: A new test statistic and a practical challenge of interpretation. 
Multivariate Behavioral Research, 50(6), 569-583. doi:

$10.1080 / 00273171.2015 .1032398$

Nafekh, M., \& Motiuk, L. L. (2002). The Statistical Information on Recidivism-Revised 1 (SIR-R1) Scale: A psychometric examination. (Report No. R-126). Retrieved from Corrections Service Canada website: http://www.cscscc.gc.ca/research/092/r126_e.pdf

Neal, T. M. S. \& Grisso, T. (2014). Assessment practices and expert judgement methods in forensic psychology and psychiatry: An international snapshot. Criminal Justice and Behavior, 41(12), 1406-1421. doi: 10.1177/0093854814548449

Nunes, K. L., Hermann, C. A., Maimone, S., \& Woods, M. (2015). Thinking clearly about violent cognitions: Attitudes may be distinct from other cognitions. Journal of Interpersonal Violence, 30(8), 1322-1347. doi: 10.1177/0886260514540329

Nunes, K. L., Hermann, C. A., Maimone, S., Atlas, M., \& Grant, B. A. (2019). The Violence Propensity Vignette Questionnaire: A measure of violent behaviour for research in forensic and non-forensic settings and populations. Submitted for publication.

Nunes, K. L., Hermann, C. A., White, K., Pettersen, C., \& Bumby, K. (2018). Attitude may be everything, but is everything an attitude? Cognitive distortions may not be evaluations of rape. Sexual Abuse: A Journal of Research and Treatment, 30(1). doi: $10.1177 / 1079063215625489$

O’Dea, C. J., Chalman, S. T., Castro Bueno, A. M., \& Saucier, D. A. (2018). Conditional aggression: Perceptions of male violence in response to threat and provocation. 
Personality and Individual Differences, 131, 132-141. doi:

10.1016/j.paid.2018.04.029

Perrault, S. (2015). Criminal victimization in Canada, 2014. Juristat. Report No. 85-002X. Retrieved from Statistics Canada: https://www150.statcan.gc.ca/n1/en/pub/85002-x/2015001/article/14241-eng.pdf?st=DM6TPsQG

Peterson, C. (2017). Exploratory factor analysis and theory generation in Psychology. Reviews of Philosophy and Psychology, 8, 519-540. doi: 10.1007/s13164-0160325-0

Piquero, A. R., Schubert, C. A., \& Brame, R. (2014). Comparing official and self-report records of offending across gender and race/ethnicity in a longitudinal study of serious youth offenders. Journal of Research in Crime and Delinquency, 51(4), 526-556. doi: 10.1177/0022427813520445

Polman, H., de Castro, B. O., Thomaes, S., \& van Aken, M. (2009). New directions in measuring reactive and proactive aggression: Validation of a teacher questionnaire. Journal of Abnormal Child Psychology, 37(2), 183-193. doi: $10.1007 / \mathrm{s} 10802-008-9266-0$

Raine, A., Dodge, K., Loeber, R., Gatze-Kopp, L., Lynam, D., Reynolds, C., StouthamerLoeber, M., \& Liu, J. (2006). The Reactive-Proactive Aggression Questionnaire: Differential correlates of reactive and proactive aggression in adolescent boys. Aggressive Behavior, 32(2), 159-171. doi: 10.1002/ab.20115

Reidy, D. E., Shelley-Tremblay, J. F., \& Lilienfeld, S. O. (2011). Psychopathy, reactive aggression, and precarious proclamations: A review of behavioural, cognitive, and 
biological research. Aggression and Violent Behaviour, 16, 512-524. doi: 10.1016/j.avb.2011.06.002

Reio Jr., T. G., \& Shuck, B. (2015). Exploratory factor analysis: Implication for theory, research, and practice. Advances in Human Resources, 17(1), 12-25. doi: $10.1177 / 1523422314559804$

Reyna, C., Ivacevich, M. G. L., Sanchez, A., \& Brussino, S. (2011). The Buss-Perry Aggression Questionnaire: Construct validity and gender invariance among Argentinean adolescents. International Journal of Psychological Research, 4(2), $30-37$.

Rieffe, C., Broekhof, E., Kouwenberg, M., Faber, J., Tsutsui, M. M., \& Guroglu, B. (2016). Disentangling proactive and reactive aggression in children using selfreport. European Journal of Developmental Psychology, 13(4), 439-451. doi: $10.1080 / 17405629.2015 .1109506$

Ruiz-Perez, I., Plazaola-Castano, J., \& Vives-Cases, C. (2007). Methodological issues in the study of violence against women. Journal of Epidemiology and Community Health, 61(2), 26-31. doi: 10.1136/jech.2007.059907

Santisteban, C., Alvarado, J. M., \& Recio, P. (2007). Evaluation of a Spanish version of the Buss and Perry Aggression Questionnaire: Some personal and situational factors related to the aggression scores of young subjects. Personality and Individual Differences, 42, 1453-1465. doi: 10.1016/j.paid.2006.10.019

Sass, D. A., \& Schmitt, T. A. (2010). Comparative investigation of rotation criteria within exploratory factor analysis. Multivariate Behavioural Research, 45(1), 73103. doi: $10.1080 / 00273170903504810$ 
Schmitt, T. A. (2011). Current methodological considerations in exploratory and confirmatory factor analysis. Journal of Psychoeducational Assessment, 29(4), 304-321. doi: 10.1177/0734282911406653

Shepherd, J. P., Shapland, M., Pearce, N. X., \& Scully, C. (1990). Pattern, severity, and aetiology of injuries in victims of assault. Journal of the Royal Society of Medicine, 83, 75-78.

Simms, L. J., Zelazny, K., Williams, T. F., \& Bernstein, L. (2019). Does the number of response options matter? Psychometric perspectives using personality questionnaire data. Psychological Assessment, [Online First]. doi: $10.1037 /$ pas0000648

Smith, G. T., McCarthy, D. M., \& Zapolski, T. C. (2009). On the value of homogeneous constructs for construct validation, theory testing, and the description of psychopathology. Psychological Assessment, 21(3), 272-284. doi:

$10.1037 / \mathrm{a} 0016699$

Soothill, K., Rodgers, P., \& Dolan, M. (Eds.). (2008). Handbook of Forensic Mental Health. Portland, OR: Willan Publishing.

Stanford, M. S., Houston, R. J., Mathias, C. W., Villemarette-Pittman, N. R., Helfritz, L. E., \& Conklin, S. M. (2003). Characterizing aggressive behaviour. Assessment, 10(2), 183-190. doi: 10.1177/1073191103252064

Tabachnick, B. G., \& Fidell, L. S. (2013). Principal Components and Factor Analysis. In Using Multivariate Statistics, $6^{\text {th }}$ Edition (p. 612-676). New Jersey, NJ: Pearson Education. 
Tapscott, J. L., Hancock, M., \& Hoaken, P. N. S. (2012). Severity and frequency of reactive and instrumental violent offending: Divergent validity of subtypes of violence in an adult forensic sample. Criminal Justice and Behaviour, 39(2), 202219. doi: $10.1177 / 0093854811429647$

Tapscott, J. L., \& Hoaken, P. N. S. (2014). Towards an improved understanding of the heterogeneity of violence: A test of the clinical utility of the reactive-instrumental distinction among adult male offenders. Doctoral dissertation. Retrieved from Electronic Thesis and Dissertation Repository. 2140. Available at: http://ir.lib.uwo.ca/etd/2140

Thornberry, T. P., \& Krohn, M. D. (2000). The self-report method for measuring delinquency and crime. In Measurement and Analysis of Crime and Justice (p. 3383). Washington DC: U.S. Department of Justice Office of Justice Programs.

Torres, W. J., \& Bergner, R. M. (2012). Severe public humiliation: its nature, consequences, and clinical treatment. Psychotherapy, 40(4), 492-501. doi: 10.1037/a0029271

Walby, S., Towers, J., Balderston, S., Corradi, C., Francis, B., Heiskanen, M., HelwegLarsen, K., Mergaert, L., Olive, P., Palmer, E., Stockl, H., \& Strid, S. (2017). The concept and measurement of violence against women and men. Bristol, UK: Policy Press.

Watson, J. C. (2017). Establishing evidence for internal structure using exploratory factor analysis. Measurement and Evaluation in Counselling and Development, 25(4), 232-238. doi: 10.1080/07481756.2017.1336931 
Webster, G. D., DeWall, C. N., Pond Jr., R. S., Deckman, T., Jonason, P. K., Le, B. M., Nichols, A. L., Schember, T. O., Crysel, L. C., Crosier, B. S., Smith, C. V., Paddock, E. L., Nezleck, J. B., Kirkpatrick, L. A., Bryan, A. D., \& Bator, R. J. (2015). The Brief Aggression Questionnaire: Structure, validity, reliability, and generalizability. Journal of Personality Assessment, 97(6), 638-649. doi:

$10.1080 / 00223891.2015 .1044093$

White, B. A., \& Turner, K. A. (2014). Anger rumination and effortful control: Mediation effects on reactive but not proactive aggression. Personality and Individual Differences, 56, 186-189. doi: 10.1016/j.paid.2013.08.012

Williams, B., Onsman, A., \& Brown, T. (2010). Exploratory factor analysis: A five-step guide for novices. Journal of Emergency Primary Health Care, 8(3), 1-13.

Wilson, M., \& Daly, M. (1998). Lethal and nonlethal violence against wives and the evolutionary psychology of male sexual proprietariness. In R. E. Dobash \& R. P. Dobash (Eds.). Rethinking violence against women, p. 199-230. Thousand Oaks, CA: SAGE Publications.

Wright, D. B., \& Harrington, J. A. (2011). Problematic standard errors and confidence intervals for skewness and kurtosis. Behavioral Research, 43, 8-17. doi: $10.3758 / \mathrm{s} 13428-010-0044-\mathrm{x}$ 


\section{Appendix A}

\section{Violence Propensity Vignette Questionnaire (VPVQ)}

\section{INSTRUCTIONS}

Please read the situations described below and say what you would really do if you were in that situation right now by choosing one of the response options.

\section{RESPONSE OPTIONS}

What do you do?

1. Report it to someone - Report what he's doing (or what he did) to someone like the manager, police, or security, and ask them to deal with the problem

2. Talk it out - Without insulting him, say something to let him know you're not okay with what he's doing (or what he did) and to try to work things out peacefully

3. Insult him - Say something insulting to him, like swearing at him or calling him a name

4. Joke about it - Joke about it to yourself or other people around you

5. Shove him

6. Hit, punch, kick, or tackle him

7. Threaten to hurt him

8. Ignore it - Don't do or say anything about it

9. Leave - Go somewhere else to get away from the person or situation 


\section{VIGNETTE 1 - OBNOXIOUS ROOMMATE}

You're living in a house with a few people. One of your roommates always takes your food and drinks from the fridge without asking, he never cleans up after himself, and he often comes home late at night making a lot of noise, which wakes you up. He's never apologized to you for any of this.

One night, at about four in the morning, he comes home drunk. This wakes you up. You go into the kitchen and you see that he's grabbing your beer and food from the fridge.

\section{Report it to someone:}

You go to your other roommate who holds the lease for the house, and you tell him what's been going on and ask him to deal with the problem. He says he'll deal with it tomorrow and falls back asleep. You leave his room. Your drunk roommate turns on the TV and puts the volume up loud.

\section{Talk it out:}

You say, "Come on, man. It's the middle of the night and you woke me up. You're making a lot of noise and you're eating my food and drinking my beer. That's not what we do. You gotta stop taking my stuff and try to keep it down so I can sleep." He tells you to "shut the fuck up" and turns the TV on loud while eating your food and finishing off your beer.

3. Insult him:

You say, "What the fuck do you think you're doing making so much noise and stealing all my shit? Stop being such an asshole, leave my stuff alone, and quiet the fuck down so I can get some sleep! Fucking douche bag."

He tells you to "shut the fuck up" and turns the TV on loud while eating your food and finishing off your beer.

4. Joke about it:

You jokingly say, "No, no, don't apologize. I didn't want to sleep. I didn't want to eat any of my food. You go ahead and enjoy it. You deserve it for being such a great roommate."

He tells you to "shut the fuck up" and turns the TV on loud while eating your food and finishing off your beer.

5. Shove him:

You push him.

He shoves you back.

6. Hit, punch, kick, or tackle him:

You hit him.

He hits you back.

7. Threaten to hurt him:

You say, "What the fuck do you think you're doing? You looking for a beating? I'm gonna kick the shit out of you if you don't leave my stuff alone and shut the fuck up."

He laughs at you and says, "Yeah right. Let's see what you got, bitch. I'm gonna knock you the fuck out."

8. Ignore it:

You go back to your bed. 
You hear him banging around in the kitchen some more. A few minutes later he turns on the TV and puts the volume up loud.

9. Leave:

You decide to go to a friend's place for the rest of the night. As you're getting ready to leave, he laughs and says, "you better keep it down or you're gonna to wake everybody up". 


\section{VIGNETTE 2 - LINE CUTTER}

You're at the store. There is a long line-up and you're close to the back of it and it's moving slow. You have been waiting in line for a while when a guy with a shopping cart full of items cuts right in front of you in the line.

\section{Report it to someone:}

You tell the store manager. The guy tells the store manager that you're lying. After the store manager leaves, the guy calls you a pussy.

\section{Talk it out:} You say, "Whoa, buddy, you just cut in front of me. I'm in line here."

He turns and looks at you and then turns back, ignoring you. He starts talking to someone on his cell phone, complaining about the long lines and saying that he just cut in front of some pussy in line.

3. Insult him:

You say, "Hey asshole! What the hell are you doing? Get to the back of the line!" He tells you to "go fuck yourself" and stays where he is.

4. Joke about it:

You jokingly say to the other people in line, "Can you believe this guy?" He tells you to "go fuck yourself" and stays where he is.

5. Shove him:

You push him.

He shoves you back.

\section{Hit, punch, kick, or tackle him:}

You hit him.

He hits you back.

10. Threaten to hurt him:

You say, "Hey asshole! What the hell are you doing? Get to the back of the line or I'm gonna knock you out!"

He laughs at you and says, "What are you gonna do? You wanna go? I'm gonna fuckin crush you."

\section{Ignore it:}

You don't say or do anything. He starts talking to someone on his cell phone, complaining about the long lines and saying that he just cut in front of some pussy in line and the guy didn't do anything about it.

8. Leave:

You decide to move to another line. As you're leaving, he starts talking to someone on his cell phone, saying that he just cut in front of some pussy in line and now he's running away. 


\section{VIGNETTE 3 - BEER BUMP}

You're at a bar when out of nowhere a guy bumps into you and spills beer on your shirt. He says "get out of my way" and starts to walk back to his table.

\section{Report it to someone:}

You tell the bar manager and ask him to deal with the guy. The bar manager says there's nothing he can do about it. You go back to the spot in the bar where you were before.

\section{Talk it out:}

You say, "You spill your beer on me and act like it's my fault? Come on. That's not right."

Hey says, "Stop crying about it and get the fuck out of here before I give you something real to cry about."

3. Insult him:

You say, "Hey! You're a fuckin' asshole!"

He says, "What the hell did you say? Get the fuck out of here before you get hurt."

4. Joke about it:

You jokingly say to the people around you, "Did you see that? What's up with that guy? I guess some people just can't handle their beer."

He sees you looking in his direction while you're joking and he gives you the finger.

5. Shove him:

You push him.

He shoves you back.

6. Hit, punch, kick, or tackle him:

You hit him.

He hits you back.

7. Threaten to hurt him:

You say, "Hey, what's your problem? You wanna get punched in the head?"

He says, "Alright asshole, let's go. I'm gonna crack your fuckin head open."

8. Ignore it:

You don't say or do anything.

He starts talking to someone at his table, points back at you, and starts laughing.

9. Leave:

You decide to leave the bar. As you're leaving, he starts talking to someone at his table, points back at you, and starts laughing. 


\section{VIGNETTE 4 - BEER RUN}

You're at a party. A guy there is going out to buy some beer. You ask him to get some beer for you too and give him $\$ 25$. When he returns hours later, he says he doesn't have your beer or your money.

\section{Report it to someone:}

You tell the guy who's hosting the party and ask him to deal with the problem.

The host says there's nothing he can do about it, and then gets called away by someone else.

\section{Talk it out:}

You say, "What happened with my beer? I'm gonna need my beer or my money back."

He says, "Well, you're shit out of luck. You're not getting any money and you're not getting any beer."

3. Insult him:

You say, "Listen, I don't care if your mom needs that money for crack. Give me back my money, you piece of shit."

He says, "What the fuck did you just say? You'll shut your fucking mouth and get out of here if you know what's good for you."

4. Joke about it:

You jokingly say to the people around you, "What just happened here? Did this guy seriously just steal \$25 from me? Who is this guy?"

He says, "What the fuck did you just say? You'll shut your fucking mouth and get out of here if you know what's good for you."

5. Shove him:

You push him.

He shoves you back.

6. Hit, punch, kick, or tackle him:

You hit him.

He hits you back.

7. Threaten to hurt him:

You say, "Give me my money back or I'll beat the shit out of you."

He says, "What the fuck did you just say? Let's go pussy. I'm gonna knock your fuckin teeth in."

8. Ignore it:

You don't say or do anything.

He starts talking to some other people at the party about what he did, points over at you, and starts laughing.

9. Leave:

You decide to leave the party. As you're leaving, he starts talking to some other people at the party about what he did, points over at you, and starts laughing. 


\section{VIGNETTE 5 - THREAT}

You're at a party. A guy walks up to you and says, "You got ten seconds to get out of here or I'm gonna to kick the shit out of you."

\section{Report it to someone:}

You tell the guy who's hosting the party and ask him to deal with the problem. The host tells you to just stay away from the guy, and then gets called away by someone else.

\section{Talk it out:}

You say, "Whoa, take it easy. You don't even know me and this isn't your house. How about you just enjoy the party and don't worry about me?"

He moves closer to you and says, "Clock's ticking, shithead. Better run away while you still can."

3. Insult him:

You say to him, "How small is your dick that you need to be acting like that? Go somewhere else and grow a dick."

He moves closer to you and says, "We'll see how funny you are when I'm kicking your head in. Clock's ticking, shithead. Better run away while you still can."

4. Joke about it:

You jokingly say to the people around you, "Wow, this guy is really not making me feel welcome at this party. Gotta talk to the host about getting a new greeter." He moves closer to you and says, "We'll see how funny you are when I'm kicking your head in. Clock's ticking, shithead. Better run away while you still can."

5. Shove him:

You push him.

He shoves you back.

6. Hit, punch, kick, or tackle him:

You hit him.

He hits you back.

7. Threaten to hurt him:

You say, "Settle the fuck down and go somewhere else before I take your fucking head off."

He moves closer to you and says, "Wrong choice, bitch. Let's go. I'm gonna fuck you up."

8. Ignore it:

You don't say or do anything.

He moves closer to you and says, "Clock's ticking, shithead. Better run away while you still can."

9. Leave:

You decide to leave the party.

As you're leaving, he says, "Only a few seconds left - better run, pussy!" 


\section{VIGNETTE 6 - UNWANTED GUEST}

You're at a party. There is a guy at the party who is bothering people and won't leave. Everyone seems to want this guy to leave. He is bothering the woman who is hosting the party. She asks him to leave but he refuses and continues to be a jerk.

\section{Report it to someone:}

You tell another guy at the party and ask him to deal with the problem.

He says there's nothing he can do about it, and then gets called away by someone else.

\section{Talk it out:}

You say to him, "Hey, bud, she wants you to leave. It's her place, so her call, right?

And you don't seem to be liking the party anyway. You should go."

He looks at you, laughs, and says, "Why is this guy talking to me? Who does this fucking guy think he is? Shut up and get away from me."

3. Insult him:

You say to him, "Hey, douche bag, she wants you to leave. Stop being such a dick and get the fuck out of here."

He looks at you, laughs, and says, "Why is this guy talking to me? Who does this fucking guy think he is? Shut up and get away from me, pussy, before I smack you in the head.'

\section{Joke about it:}

You jokingly say to the people around you, "Who made the mistake of inviting this guy to the party?"

He looks at you and says, "You got something to say there, pussy?"

5. Shove him:

You push him.

He shoves you back.

6. Hit, punch, kick, or tackle him:

You hit him.

He hits you back.

7. Threaten to hurt him:

You say to him, "Hey, douche bag, she wants you to leave. Stop being such a dick and get out of here, or I'll throw you out."

He looks at you, laughs, and says, "You're gonna throw me out? You?! Go for it. I'm gonna beat the shit out of you."

8. Ignore it:

You don't say or do anything.

He continues bothering the host and other people, and the host keeps telling him to leave.

9. Leave:

You decide to leave the party.

As you're leaving, he continues bothering the host and other people, and the host keeps telling him to leave. 


\section{VIGNETTE 7 - OBNOXIOUS GUY IN LINE}

You're waiting in line in the store. The person behind you is talking to his friend really loudly and rudely. He is standing very close to you and he keeps bumping you with his arms as he moves around while talking to his friend.

\section{Report it to someone:}

You tell the store manager. The store manager asks the guy to be more quiet. The guy says okay, and the store manager leaves. The guy taps you on the shoulder and asks, "You gonna go cry to your mother next?" and starts laughing with his friend and goes right back into talking loudly and rudely and getting in your space.

2. Talk it out:

You say to him, "Come on, man, what are you doing? You gotta stop talking like that and give me some room."

He laughs at you and says, "Oh yeah, well, you gotta turn around and mind your own fucking business."

\section{Insult him:}

You say to him, "What are you doing, asshole? Back the fuck up and save your stupid fucking stories for out in the parking lot when you and your buddy are jackin each other off."

He says, "Nobody's talking to you, pussy. Shut the fuck up, turn around, and mind your own fucking business, if you know what's good for you."

4. Joke about it:

You jokingly say to the people around you, "Nice way to talk in the store with women and children around. Real classy."

He says, "Nobody's talking to you, pussy. Shut the fuck up and mind your own fucking business."

5. Shove him:

You tell him to shut up and push him.

He shoves you back.

6. Hit, punch, kick, or tackle him:

You tell him to shut up and hit him.

He hits you back.

7. Threaten to hurt him:

You say, "What are you doing, asshole? Back the fuck up and save your stupid fucking stories for out in the parking lot when you and your buddy are jackin each other off. Bump into me one more time and I'll kick your ass."

He says, "What are you gonna do, pussy? I'm gonna smash your fuckin face in."

8. Ignore it:

You don't say or do anything.

The guy says something about you to his friend and they both start laughing.

9. Leave:

You decide to leave.

As you're leaving, the guy says something about you to his friend and they both start laughing. 


\section{VIGNETTE 8 - INTIMATE PARTNER VIOLENCE}

You are at a party. You notice a couple at the party fighting, and the guy seems to be very angry at the woman. He starts yelling at her and calling her names, and accusing her of cheating on him. Then the guy slaps the woman in the face.

\section{Report it to someone:}

You call the police and report it. They say they'll send an officer later and hang up.

2. Talk it out:

You say to him, 'Did you really just slap her? That's really messed up, man. You gotta leave."

He says, "Fuck off and mind your own business. You should worry about what your own slutty bitch is doing right now."

3. Insult him:

You say to him, "What kind of fuckin psycho hits a woman? What's your fucking problem, man? Leave her alone, you piece of shit."

He says, "Fuck off and mind your own business. You should worry about what your own slutty bitch is doing right now."

\section{Joke about it:}

You say to the people around you, "Did everybody see that? Who hits a woman? What's wrong with this psycho?"

He says, "Fuck off and mind your own business. You should worry about what your own slutty bitch is doing right now."

\section{Shove him:}

You push him.

He shoves you back.

6. Hit, punch, kick, or tackle him:

You hit him.

He hits you back.

7. Threaten to hurt him:

You say to him, "What the fuck are you doing? Leave her alone or I will beat the living shit out of you."

He says, "Fuck off and mind your own business. I'm gonna knock you out as soon as I'm done with this whore."

\section{Ignore it:}

You don't say or do anything.

He continues to yell at her and he hits her again.

9. Leave:

You decide to leave.

As you're leaving, he continues to yell at her and he hits her again. 


\section{VIGNETTE 9 - INTERLOPER}

You're at a bar standing beside your girlfriend/wife when a guy walks up to her, puts his arm around her, and starts trying to pick her up. He acts like you aren't even there.

\section{Report it to someone:}

You tell the bar manager and ask him to deal with the guy. The bar manager says there's nothing he can do about it. The guy tells your girlfriend/wife that you're a loser and asks her to dance.

\section{Talk it out:}

You say to him, "Buddy, what are you doing? You know she's with me. Go talk to someone else."

He ignores you, steps between you and your girlfriend/wife, turns his back to you, tells her that you're a loser, and asks her to dance.

3. Insult him:

You say to him, "Are you a fucking idiot? What's wrong with you? Get the fuck out of here and find your own woman."

He ignores you, steps between you and your girlfriend/wife, turns his back to you, tells her that you're a loser, and asks her to dance.

4. Joke about it:

You jokingly say, “That's right. Come over here and hit on the girl who's with someone already. Real fuckin' smart."

He ignores you, steps between you and your girlfriend/wife, turns his back to you, tells her that you're a loser, and asks her to dance.

5. Shove him:

You push him.

He shoves you back.

6. Hit, punch, kick, or tackle him:

You hit him.

He hits you back.

\section{Threaten to hurt him:}

You say to him, "Are you a fucking idiot? What's wrong with you? Start showing some fuckin respect or I'll kick the shit out of you."

He says, "Yeah, what are you gonna do? I'll fucking punch you out. Listen, you're gonna go get some drinks for the lady and me, and then stay the fuck out of our way."

8. Ignore it:

You don't say or do anything.

He steps between you and your girlfriend/wife, turns his back to you, tells her that you're a loser, and asks her to dance.

9. Leave:

You decide to leave.

As you and your girlfriend/wife are leaving, the guy says to your girlfriend/wife, "Don't leave with that loser. You're too hot for that guy. You can do so much better." 


\section{VIGNETTE 10 - DISRESPECTING YOUR GIRLFRIEND/WIFE}

You're at a bar. You overhear a guy talking about your girlfriend/wife. He is saying that she looks like a real slut and that she probably loves to suck cock. He says he bets he can get her to give him a blowjob in the washroom.

\section{Report it to someone:}

You tell the bar manager and ask him to deal with the guy. The guy tells the bar manager that you're lying. After the bar manager leaves, the guy says that you'll probably want to give him a blowjob too.

\section{Talk it out:}

You say, "That's my girlfriend you're talking about. Come on, man, have some respect."

He says, "Hey relax man - just kidding around." But a few seconds later, he says, "Spits or swallows? I bet she swallows."

3. Insult him:

You say, "What's your fucking problem, man? I think maybe you're the cocksucker. Go jam a dick in your mouth already and shut the fuck up."

He says, "Hey, relax man. Don't worry. I don't want to keep her. She can still go home with you after she blows me a few times."

4. Joke about it:

You jokingly say to nobody in particular, "Classy place. I like the energy. This creepy guy over here talking shit about the women. Nice touch. Makes you feel welcome. Well done." He says, "Spits or swallows? I bet she swallows."

5. Shove him:

You push him.

He shoves you back.

6. Hit, punch, kick, or tackle him:

You hit him.

He hits you back.

7. Threaten to hurt him:

You say, "Hey asshole! Watch your fucking mouth! That's my girlfriend you're talking about. If I hear you talking like that again, I'll kick your ass."

He says, "Yeah, you wanna go? I'm gonna stomp your fucking face and then your lady's gonna blow me in your car."

8. Ignore it:

You don't say or do anything.

He says, "Spits or swallows? I bet she swallows."

9. Leave:

You decide to leave.

As you and your girlfriend/wife are leaving, he says, "Spits or swallows? I bet she swallows." 


\section{Appendix B}

\section{Physical Aggression Scale of the Aggression Questionnaire}

$\begin{array}{lllll}1 & 2 & 3 & 4 & 5\end{array}$

Not at all

A bit like me Very much

like me and a bit not like me like me

1. Once in a while I can't control the urge to strike another person

2. Given enough provocation, I may hit another person

3. If somebody hits me, I hit back

4. I get into fights a little more than the average person

5. If I have to resort to violence to protect my rights, I will

6. There are people who pushed me so far that we came to blows

7. I can think of no good reason for ever hitting a person ${ }^{r}$

8. I have threatened people I know

9. I have become so mad that I have broken things

10. Please press the number "four" *

${ }^{\mathrm{r}}$ Reverse scored item

* Quality-control question. 


\section{Appendix C}

\section{Violent Behaviour Scale}

Response Scale
$1=$ Once
$2=$ Twice
$3=$ Three times
$4=$ Four times
$5=$ Five times
$6=$ Six times
$7=$ Seven times
$8=$ Eight times
$9=$ Nine times or more
$0=$ Never

From when you were 16-years old to today, how many times have you

1. Started a physical fight with someone?

2. Threatened to physically hurt someone?

3. Hit someone with the intention of hurting them?

4. Thrown objects such as rocks or bottles at someone with the intention of hurting them?

5. Used a weapon or force to make someone give you money or items?

6. Injured someone on purpose (e.g., left bruises, caused visible bleeding or broken bones, etc.)? 
7. Been arrested for a violent offence (e.g., assault)?

8. Been convicted of a violent offence (e.g., assault)?

9. Please press the number "three" *

* Quality-control question. 


\section{Appendix D}

\section{EFA Results and Factor Loadings for the 2- and 3-Factor Models for the VPVQ}

\section{Response Options}

Table D 1.

Fit Statistics and Factor Correlations for Exploratory Factor Analysis with Oblique Rotation of VPVQ Response Options (2- and 3-Factor)

\begin{tabular}{lcc}
\hline & 2-Factor Model & 3-Factor Model \\
\cline { 2 - 3 } Eigenvalues & .968 & .619 \\
Fit Statistics & & \\
RMSEA & $.009,95 \% \mathrm{CI}[.0001, .042]$ & $.008,95 \%$ CI [.0001,.049] \\
CFI & 1.00 & 1.00 \\
SRMR & .037 & .028 \\
Factor correlations & $r=.63 *$ & ${ }^{a} r_{\mathrm{F} 1 / \mathrm{F} 2}=.79^{*}$ \\
& & ${ }^{b}{ }{ }_{\mathrm{F} 1 / \mathrm{F} 3}=.51$ \\
& & ${ }^{c} r_{\mathrm{F} 2 / \mathrm{F} 3}=.63^{*}$ \\
\hline
\end{tabular}

Note. ${ }^{*} p<.05 ;$ RMSEA $=$ Root Mean Square Error Approximation; CFI $=$

Comparative Fit Index; SRMR = Standardized Root Mean Square Residual; $r=$

Pearson's correlation coefficient; $\mathrm{CI}=$ confidence interval

${ }^{\mathrm{a} C}$ Correlation for factors 1 and 2

${ }^{\mathrm{b}}$ Correlation for factors 1 and 3

${ }^{\mathrm{c}}$ Correlation for factors 2 and 3

Table D 2.

Factor Loadings for Exploratory Factor Analysis with Oblique Rotation of VPVQ Response Options (2-Factor)

\begin{tabular}{lcc}
\hline & \multicolumn{2}{c}{ Rotated factor loadings } \\
\cline { 2 - 3 } Response Option & Factor 1 & Factor 2 \\
\hline 1. Report & $.78 \dagger$ & .009 \\
2. Talk & $.68 \dagger$ & .014 \\
3. Insult & $.83 \dagger$ & -.07 \\
4. Joke & $.73 \dagger$ & .05 \\
5. Shove & $.59 \dagger$ & .26 \\
6. Hit/punch/kick & .27 & $.56 \dagger$ \\
7. Threaten & $.86 \dagger$ & -.20 \\
8. Ignore & -.001 & $.81 \dagger$ \\
9. Leave & $.45 \dagger$ & $.44 \dagger$ \\
\hline
\end{tabular}

Note. ' $\dagger$ ' denotes factor loadings greater than .40. Unstandardized factor loadings are provided due to the dichotomous nature of the data, and the use of oblique rotation. 
Table D 3.

Factor Loadings for Exploratory Factor Analysis with Oblique Rotation of VPVQ Response Options (3-Factor)

\begin{tabular}{lccc}
\hline & \multicolumn{3}{c}{ Rotated factor loadings } \\
\cline { 2 - 4 } Response Option & Factor 1 & Factor 2 & Factor 3 \\
\hline 1. Report & $.72 \dagger$ & -.01 & .22 \\
2. Talk & $.56 \dagger$ & .027 & .21 \\
3. Insult & .05 & $.79 \dagger$ & -.007 \\
4. Joke & .10 & $.58 \dagger$ & .16 \\
5. Shove & -.04 & $.55 \dagger$ & .36 \\
6. Hit/punch/kick & .14 & .01 & $.67 \dagger$ \\
7. Threaten & $.54 \dagger$ & .26 & -.01 \\
8. Ignore & -.002 & -.15 & $.90 \dagger$ \\
9. Leave & .02 & .32 & $.55 \dagger$ \\
\hline
\end{tabular}

Note. ' $\uparrow$ ' denotes factor loadings greater than .40 . Unstandardized factor loadings are provided due to the dichotomous nature of the data, and the use of oblique rotation. 


\section{Appendix E}

\section{Descriptive Statistics Table for the Continuous Variable VPVQ Response Options}

Descriptive Statistics for the Continuous Variable VPVQ Response Options $(N=471)$

\begin{tabular}{lcccccc}
\hline Item & $M(S D)$ & Median & Min & Max & Skewness & Kurtosis \\
\hline Report it & $2.63(3.70)$ & 1.00 & 0.00 & 20.00 & 2.78 & 9.16 \\
Talk it out & $6.34(4.15)$ & 6.00 & 0.00 & 20.00 & 0.92 & 0.97 \\
Insult him & $1.92(2.18)$ & 1.00 & 0.00 & 10.00 & 1.10 & 0.64 \\
Joke about it & $1.00(1.69)$ & 0.00 & 0.00 & 12.00 & 2.79 & 10.60 \\
Shove him & $0.92(1.33)$ & 0.00 & 0.00 & 7.00 & 1.88 & 4.09 \\
Hit/punch/kick & $2.42(3.13)$ & 1.00 & 0.00 & 18.00 & 1.66 & 3.20 \\
him & & & & & & \\
Threaten him & $1.10(1.47)$ & 0.00 & 0.00 & 7.00 & 1.47 & 1.78 \\
Ignore it & $1.87(2.27)$ & 1.00 & 0.00 & 16.00 & 1.79 & 4.74 \\
Leave & $1.72(2.60)$ & 1.00 & 0.00 & 20.00 & 2.74 & 10.39 \\
\hline
\end{tabular}

Note. $\mathrm{M}=$ mean; $\mathrm{SD}=$ standard deviation; $\mathrm{Min}=$ smallest value; $\mathrm{Max}=$ largest value 